\title{
Review
}

\section{Energy in buildings: A review of models on hygrothermal transfer through the porous materials for building envelop}

\author{
Macmanus Chinenye Ndukwu ${ }^{1}$, Merlin Simo-Tagne 2,*, Ifiok Edem Ekop ${ }^{3}$, Mathew. I. Ibeh ${ }^{4}$, Maureen A. Allen ${ }^{4}$, \\ Fidelis. I. Abam ${ }^{4}$ and Razika Kharchi ${ }^{5}$ \\ 1 Department of Agricultural and Bioresources Engineering, Michael Okpara University of Agriculture, \\ P.M.B. 7267, Umuahia, Nigeria; ndukwumcu@mouau.edu.ng \\ 2 LERMaB, ENSTIB, 27 rue Philippe Séguin, PO Box 1041, F-88051 Epinal, France ; simotagne2002@yahoo.fr \\ 3 Department of Building, University of Uyo, Akwa Ibom State, Nigeria; ifiokekop@uniuyo.edu.ng \\ 4 Department of Mechanical Engineering, Michael Okpara University of Agriculture, P.M.B. 7267, Umuahia, \\ Nigeria; abamfidelis@mouau.edu.ng (Abam); mathewibeh@gmail.com (Ibeh); allen@mouau.edu.ng (Allen) \\ 5 Centre de Développement des Energies Renouvelables, CDER, B.P. 62, Route de l'Observatoire, 16340 Bou- \\ zaréah, Alger, Algérie ; razkharchi@yahoo.fr \\ * Correspondence: simotagne2002@yahoo.fr, Merlin.Simo-Tagne@ac-nancy-metz.fr; Tel.: 0033644911921
}

\begin{abstract}
The hygrothermal transfer is very important for the design of a building envelope for thermal comfort and economic and energy analysis of the building envelope. The applications of various materials in building envelope have been studied extensively. The study presents several models for the hygrothermal transfer for various building walls. Several energy and mass conservation equations with different boundary conditions and input considerations were presented in this paper for concrete, bricks and wooden walls. The effect of hysteresis was ignored in developing most model equations, while few considered flow pattern of fluid through the wall surfaces. Due to the flexibility of Luikov models, it formed the basis for modelling the coupled heat and mass transfer for porous material independent of hygroscopic nature with different boundary conditions defined according to the geometry and orientations. The influence of type of wall, orientation, thickness, the density of the material and climatic variations on the temperature and moisture evolutions within the building materials was more pronounced. Literature, presenting imaging models using imagery software like COMSOL multi-physics, CFD etc. were scarce considering that microscopic imagery is now deployed to measure the heat and moisture evolution in materials. Future models should include shrinkage or expansion influence on the fibrous material like wood due to their behaviour under environmental condition.
\end{abstract}

Keywords: porous materials; building wall; modelling; heat and mass transfer; green building

\section{Introduction}

All over the globe, structures such as housing, storage cabin for agricultural products (barns, concrete silos, mud rhombus etc.), animal houses etc. utilizes much energy for their life span. As the global population grows, more demand is placed on energy supply. Strains are imposed on both renewable and non-renewable energy resources. Therefore, energy efficiency within the building envelope has been advocated all over the world due to the large energy demand of the building and construction sector and the overall greenhouse gas emitted through the process to the environment [1]. Some researchers have estimated that building alone consumes about $36-40 \%$ of global energy, generating close to $50 \%$ of global greenhouse gas emission [1, 2]. However, in some countries, the IEA report has revealed that energy utilization in building alone consume over $70 \%$ of the total available energy in those countries releasing a large amount of greenhouse gas into the environment [3]. Energy demands in a building can be categorized into energy utilization in the constructions phase and energy utilization in the operational phase [1]. Researchers 
have noted that the operational phase of a building consumes 75-90\% of the energy in a building while the rest comes from material extraction, production, construction, transportation and the end of the life span of the building $[1,4,5]$. However, in the operational phase, the aspect of building that consumes a lot of energy is the cooling [6, 7] of building structures in tropical environment and heating of building in temperate zones. The global requirement for energy in cooling houses rose to about $11000 \mathrm{GW}$ in 2016 from $4000 \mathrm{GW}$ in $1990[8,9]$.

The demand for energy efficiency in building structure has become more imperative because of the need to tame the global production of greenhouse gases produced during energy generation caused by building activities. There is the need to reduce globally the environmental impact caused directly or indirectly by building, through the development of a green strategy to enhance energy efficiency utilization on buildings. Although most researchers in this area have looked at the energy generation impact on transportation, manufacturing, construction and operational phases of the building on greenhouse generation on the environment, others have included, the acidification of the environment, depletion of the ozone layer, global warming, abiotic resources reduction, eutrophication etc.[1, 10-11]. Therefore emphasis is targeted on cutting down energy utilization in a building. Countries are adopting a green strategy in building, hoping to cut down energy consumption by $20-42 \%$ by 2050 with a $35 \%$ reduction in greenhouse emission $[12,13]$. Different strategies have been adopted by researchers in this area. While some has considered the entire structural envelop, others have looked at the materials for construction or various components of the structures ranging from the walls, the floor or the roof envelop $[9,14$, and 15].

Another challenge faced by building developers besides energy utilization is the issue of moisture adsorption within the building envelope for hygroscopic materials. Condensations inside the building envelop is most common due to variation of temperature and humidity of the indoor and the outside of the building. The presence of moisture within the building envelope will cause thermal discomfort and can corrode the metallic structures within the building and also make the indoor mouldy [16]. This can lead to structural degradation and failure. Therefore the study of heat and mass transfer between the porous materials interface is done to elucidate their thermal performance and strength. The discontinuous moisture profile of two porous materials at the interface because of their hygroscopic characteristics has been used to predict the temperature and moisture gradients. Therefore, it is obvious that the nature of the materials used in building construction affects the temperature and moisture variations within the building as a function of the ambient weather changes and by extension the energy required for cooling or heating satisfaction $[9,17]$. Therefore it can determine the magnitude of humidity, heating and cooling required $[18,19]$.

Materials like wood, metal, steel, concrete, pozzolan, glass, bricks and other multilayered composites have been adopted for building walls [20-25]. Osayintola et al [26] and Lelievre et al [17] classified building materials as classical and hygroscopic building materials. Lelievre et al [17] further sub-classified the building materials as bio-based and non-bio based materials. The authors stated that bio-based materials like hemp concrete have potential low carbon emission, good thermo-hydric properties and moisture buffering properties [27-30]. In several cases walls can be made of more than one materials layer, considering building insulations and cement plasters in some walls. Insulated walls (Figure 1) will regulate the heat and moisture transfer within the building envelope. 


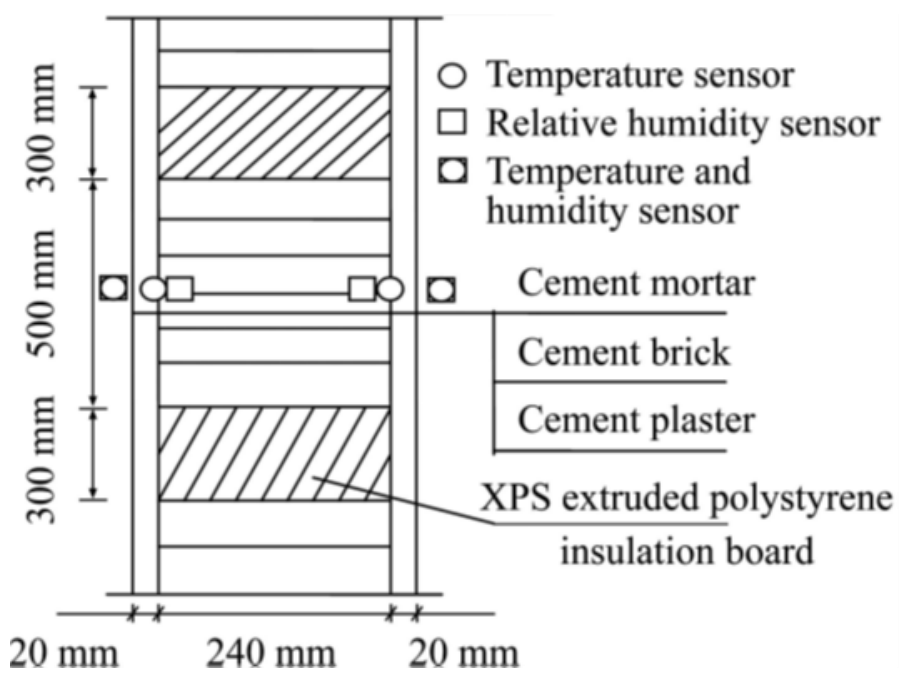

Figure 1. A typical building wall insulated with polystyrene [20].

Therefore experimental and numerical studies have been carried out to study the characteristics of heat and moisture transfer of various materials in response to variation in weather parameters which includes, solar radiation, temperature, moisture and relative humidity. Therefore studies on the hygrothermal transfer through different building walls have been presented in the literature [3143, 16, 44-52]. Most of the studies developed predictive models to determine the temperature, relative humidity and moisture condition of the inside of the building as a variation to the ambient conditions [32-34, 36-43]. The various studies used the thermo-physical properties of these materials to develop the simulation models to make their predictions with good result. The vapour adsorption and desorption isotherm is controlled by the main adsorption isotherm with the occurrence of hysteresis in the sorption curves [17]. Although the nature of the hysteresis is yet well established, some authors included it in their modelling approach while others neglected it. Simo-Tagne et al. [9] stated that studies like this will help in the selection of materials to satisfy the desired heat load at minimum dissipation of energy with less environmental impact. Therefore this research is focused on the presentation and review of various studies and models developed for different building walls made from different materials used in wall construction. This will help to elucidate different model approach adopted and help to improve building design to conserve energy and achieve satisfactory living comfort at minimum operating conditions.

\section{Hygrothermal transfer models for concrete and brick walls}

There exists several modelling and simulation investigation with a different approach for concrete and bricks based walls in literature. To reduce energy consumption or improve hygrothermal transfer in buildings, researchers have developed different kinds of wall composite. Walls can be single, double or multilayer. A multilayer wall is a wall made up of more than one porous material. Concrete (bio-based and non-bio-based), bricks, cement plasters etc can be used to develop a multilayer wall. These walls have also been numerically simulated to obtain different varying conditions for indoor and outdoor conditions and the results of the models validated experimentally. Xingguo et al[20] modelled a multi-layered porous wall made of cement mortar, red bricks and cement plaster in the southern Chinese city of Hunan. The model developed was a modified one dimensional transient hygrothermal model with temperature and humidity as the driving potential. Two key transport equations (1 and 3) for mass and heat transport respectively were solved using the finite element with established boundary conditions and the thermophysical properties of these materials. The maximum temperature and humidity difference obtained by the researchers were $1.87{ }^{\circ} \mathrm{K}$ and $11.4 \%$ for indoor and outdoor condition.

$\frac{\partial W}{\partial t}=\frac{W_{s}}{\xi \rho_{m}}\left(D_{v} R_{v} T_{m} \rho_{a}+\frac{\xi \rho_{m}}{W_{s}} D_{w}\right) \frac{\partial^{2} W}{\partial x^{2}}+\phi \frac{\partial W_{s}}{\partial T} \frac{\partial T}{\partial t}$

The resultant boundary conditions for the above equation were given as follows: 
$-D_{v} R_{v} T_{m} \rho_{a} \frac{\partial W}{\partial x}=h_{m}\left(W_{\infty}-W_{\text {surf }}\right)$

Where $\phi$ is the relative humidity, $\mathrm{T}$ is temperature $\xi$ is the slope of moisture equilibrium curve, Ws is the saturation moisture content of air, $t$ is time, $\mathrm{W}$ is Air humidity ratio, $\mathrm{Dv}$ is the vapour diffusion coefficient of the material, $\mathrm{Rv}$ is the water vapour characteristic constant, oa is the density of air, om is the density of the material, Tm is the temperature of the material, Dw is the liquid diffusivity coefficient of the material, $\mathrm{Cm}$ is the volumetric moisture capacity, $\mathrm{hm}$ is the mass transfer coefficient, $\mathrm{x}$ is location.

For the heat transport, the following governing equation was used

$\left(\rho_{m} C_{v m}\right) \frac{\partial T}{\partial t}=K \frac{\partial^{2} T}{\partial x^{2}}+h_{f g} D_{v} R_{v} T_{m} \rho_{a} \frac{\partial^{2} W}{\partial x^{2}}$

The resultant boundary conditions for the above equation were given as follows

$-K \frac{\partial T}{\partial x}=h_{m}\left(T_{\infty}-T_{\text {surf }}\right)+Q_{\text {rad }}+h_{f g} m_{s}$

Where Qrad is direct solar heat gain, $m s$ is the rate of mass transfer at the surface of the wall, $\mathrm{K}$ is the thermal conductivity.

Lelievre et al [17] combined two sub-models of Pederson and phenomenological model developed Mualem to develop a numerical simulation model for multilayer hemp concrete. Hemp concrete is usually coated with plasters of different level of permeability inside and outside and the thickness is non-homogenous [17]. The model developed which accounted for phase change and hysteresis depended on the temperature and moisture transfer as a function of the hygrothermal properties of the hemp. They gave the energy and moisture conservation equations as follows

$\rho_{s}\left(C_{p, s}+w C_{p, l}\right) \frac{\partial T}{\partial t}=-\nabla \times(-\lambda \nabla T)+-\nabla \times\left(D_{v}^{\varphi} \nabla \varphi+D_{v}^{T} \nabla T\right) \times\left(l_{v}+\left(C_{p, s}-C_{p, l}\right)(T-\right.$ $\left.T_{\text {ref }}\right)$ )

$\rho_{s} \theta \frac{\partial \varphi}{\partial t}=-\nabla \times\left(-\left(D_{l}^{\varphi}+D_{v}^{\varphi} \nabla T\right) \nabla \varphi-D_{v}^{T} \nabla T\right)$

Where $\varrho_{s}$ is the apparent density of the material, $\mathrm{D} v$ is the Vapor diffusion coefficients, $\mathrm{w}$ is the moisture and $\boldsymbol{\theta}$ is the sorption capacity $l_{v}$ is the heat of vaporization at the reference temperature Tref.

The sorption capacity of equations 6 was deduced using two hysteresis models in sorption and desorption phases from Pederson (equation 7 and 8) and Mualem (equations 9 and 10) as follows

$\boldsymbol{\theta}_{\text {ad,hys }}=\frac{B\left(w-w_{a d}\right)^{A} \boldsymbol{\theta}_{\text {des }}+\left(w-w_{\text {des }}\right)^{A} \boldsymbol{\theta}_{\text {ad }}}{\left(\boldsymbol{w}_{\text {des }}-w_{\text {ad }}\right)^{A}}$
$\boldsymbol{\theta}_{\text {ad,hys }}=\frac{\left(\boldsymbol{w}-\boldsymbol{w}_{\text {ad }}\right)^{A} \boldsymbol{\theta}_{\text {des }}+C\left(\boldsymbol{w}-w_{\text {des }}\right)^{A} \boldsymbol{\theta}_{\text {ad }}}{\left(\boldsymbol{w}_{\text {des }}-\boldsymbol{w}_{\text {add }}\right)^{A}}$

Where $\mathrm{Wdes}_{\text {des }}$ and Wad are the adsorption and desorption moisture isotherms for a particular relative humidity. A B and C are coefficients determined empirically. Using Mualem models, the following sorption equations were deduced

$$
\begin{aligned}
& w_{\text {des, hys }}(\varphi)=w_{j}-\frac{p_{d}}{w_{s}}\left(w_{s}-w_{a d}(\varphi)\right)\left(w_{a d}\left(\varphi_{j}\right)-w_{a d}(\varphi)\right) \\
& w_{a d, h y s}(\varphi)=w_{j}-\frac{w_{j}-w_{i}}{\left(w_{a d}\left(\varphi_{j}\right)-w_{a d}(\varphi)\right)}\left(w_{a d}\left(\varphi_{j}\right)-w_{a d}(\varphi)\right)
\end{aligned}
$$

Where $\varphi_{\mathrm{i}}$ and $\varphi_{\mathrm{j}}$ is the minimum and maximum values of the relative humidity while $\mathrm{W}_{\mathrm{i}}$ and $\mathrm{w}_{\mathrm{j}}$ are the minimum and maximum values of moisture content respectively in the adsorption-desorption cycle. $P_{d}$ is a function that depends on pore water blockage against air entry, while $\mathrm{w}_{\mathrm{s}}$ is the saturated moisture content. 
Validation of the above models showed that using sorption isotherm from Mualem gave a good agreement between the experimental and predicted results while the model of Pederson was off the mark.

Djongyang et al [42] presented a hygrothermal transfer model for porous building components which they validated with earth bricks wall. They considered a plane geometrical shape and the influence of inter-tropical condition with variations in latitude for the three cities of Cameroon. In solving the numerical equations, they considered the periodic solution approach and validated their model with two works of Menghao et al [45, 50]. The model developed was one dimensional in which liquid water and air and water vapour as a single binary gas mixture was considered. The conservation equations for mass and heat transport were taken from the equation of Luikov which has been used by other researchers [52] as follows

$$
\begin{aligned}
& \frac{\partial u(x, t)}{\partial x}=a_{m} \frac{\partial^{2} u(x, t)}{\partial x^{2}}+a_{m} \delta \frac{\partial^{2} T(x, t)}{\partial x^{2}} \\
& \frac{\partial T(x, t)}{\partial t}=\alpha \frac{\partial^{2} T(x, t)}{\partial x^{2}}+\varepsilon \beta \frac{\partial u(x, t)}{\partial t}, \quad 0<x<l
\end{aligned}
$$

The boundary conditions for the two equations above were defined as follows

$-\left.k_{\text {qout }} \frac{\partial T(x, t)}{\partial x}\right|_{\mathrm{x}=0}+h_{\text {out }}\left(T_{x=0}-T_{\text {out }}\right)+\lambda_{\text {out }}\left(1-\varepsilon_{\text {out }}\right)\left(u_{x=0}-u_{\text {out }}\right)=0$

$\left.k_{\text {mout }} \frac{\partial u(x, t)}{\partial x}\right|_{\mathrm{x}=0}+\left.k_{\text {mout }} \delta_{\text {out }} \frac{\partial T(x, t)}{\partial x}\right|_{\mathrm{x}=0}+\alpha_{\text {out }}\left(u_{x=0}-u_{\text {out }}\right)=0$

$-\left.k_{\text {qin }} \frac{\partial T(x, t)}{\partial x}\right|_{\mathrm{x}=0}+h_{\text {in }}\left(T_{x=0}-T_{\text {in }}\right)+\lambda_{\text {in }}\left(1-\varepsilon_{\text {in }}\right)\left(u_{x=0}-u_{\text {in }}\right)=0$

$\left.k_{\min } \frac{\partial u(x, t)}{\partial x}\right|_{\mathrm{x}=0}+\left.k_{\min } \delta_{i n} \frac{\partial T(x, t)}{\partial x}\right|_{\mathrm{x}=0}+\alpha_{i n}\left(u_{x=0}-u_{i n}\right)=0$

Where $\mathrm{T}$ is temperature, $\mathrm{t}$ is time $\mathrm{am}$ is moisture diffusion coefficient $(\mathrm{m} 2 / \mathrm{s}), \mathrm{h}$ is convective heat coefficient $\left(\mathrm{W} / \mathrm{m}^{2} \mathrm{~K}\right), \mathrm{km}$ is moisture conductivity $(\mathrm{kg} / \mathrm{m} \mathrm{s}), \mathrm{k}_{\mathrm{q}}$ is thermal conductivity $(\mathrm{W} / \mathrm{kg} \mathrm{K}), \mathrm{I}$ is the thickness $(\mathrm{m}), \mathrm{u}$ is moisture rate $(\mathrm{kg} / \mathrm{kg}), \mathrm{x}$ is the distance $(\mathrm{m})$, $\boldsymbol{\alpha}$ is thermal diffusivity $(\mathrm{W} \mathrm{m} 2 / \mathrm{J}), \boldsymbol{\delta}$ is thermogradient coefficient $\left(\mathrm{K}^{-1}\right), \boldsymbol{\varepsilon}$ is the phase change coefficient, $\lambda$ is the heat of phase change $(\mathrm{J} / \mathrm{kg})$

Equations 13 and 15 represent the heat balance with the three components of the quantity of heat exchanged for outdoor and indoor, the convective heat transfer and evaporative flux while equations 14 and 16 represents the mass balance with the components of moisture gradient, temperature gradient and the convective flux exchanged between the ambient and the surface of the materials. Djongyang et al [42] considering the length of the day and the declination of the sun converted equations 11 and 12 to oscillatory (periodic) equations using the Fourier series method as presented in equations 17 and 18 which they used in their validation adopting a periodic approach

$\frac{\partial^{2} u_{n}(x)}{\partial x^{2}}-\frac{i n w}{a_{m}} u_{n}+\delta \frac{\partial^{2} T_{n}(x)}{\partial x^{2}}=0$
$\frac{\partial^{2} T_{n}(x)}{\partial x^{2}}-\frac{i n w}{\alpha} T_{n}+\varepsilon \beta \frac{i n w}{\alpha} u_{n}=0$

Where $w$ is frequency over a whole day cycle.

Using a numerical approach they solved equations 17 and 18 to generate the temperature and moisture profile of the material under the variable external conditions. Validation of the results using thermo-physical properties of earth bricks gave good results. They showed that latitudes affect the hygrothermal transfer.

Menghao et al [45] also used the same one-dimensional Lukoiv equation presented in equations 11 and 12 in the modelling of a hygrothermal transfer for a fibrous slab but they added the effect of adsorption and desorption heat which is also one of the source or sink terms in coupled heat and mass transfer equations. They assumed a localized thermodynamic equilibrium between the fluid and the porous matrix in presenting the equations as follows.

$C_{P} \rho \frac{\partial T}{\partial t}=k \frac{\partial^{2} T}{\partial x^{2}}+C_{m} \rho\left(\epsilon h_{l v}+\gamma\right) \frac{\partial m}{\partial t}$ 
$C_{m} \rho \frac{\partial m}{\partial t}=D_{m} \frac{\partial^{2} m}{\partial x^{2}}+D_{m} \delta \frac{\partial^{2} T}{\partial x^{2}}$

The latent heat of vaporization will be integrated as part of the energy balance at the building materials boundary which will be affected by the mass diffusion due to deviation in temperature and moisture content $[42,53]$. The boundary equations were given as follows

$\left.k \frac{\partial T(x, t)}{\partial x}\right|_{\mathrm{x}=0}=\alpha_{1}\left(T(0, t)-T_{1}\right)+\beta_{1} h_{l v}(1-\varepsilon)\left(m(0, t)-m_{1}\right)$

$-\left.k \frac{\partial T(x, t)}{\partial x}\right|_{\mathrm{x}=0}=\alpha_{2}\left(T(l, t)-T_{2}\right)+\beta_{2} h_{l v}(1-\varepsilon)\left(m(l, t)-m_{2}\right)$

$\left.D_{m} \frac{\partial T(x, t)}{\partial x}\right|_{\mathrm{x}=0}+\left.k_{m} \delta \frac{\partial T(x, t)}{\partial x}\right|_{\mathrm{x}=0}=\beta_{1}\left(m(0, t)-m_{1}\right)$

$-\left.D_{m} \frac{\partial T(x, t)}{\partial x}\right|_{\mathrm{x}=0}-\left.k_{m} \delta \frac{\partial T(x, t)}{\partial x}\right|_{\mathrm{x}=0}=\beta_{2}\left(m(l, t)-m_{2}\right)$

Where $C_{m}$ is the specific moisture, $C_{p}$ is the specific heat, $D_{m}$ is the conductivity coefficient of moisture content, $h$ is the latent heat, $h_{l v}$ is the heat of phase change, $k$ is the thermal conductivity, 1 is the thickness of the specimen, $\mathrm{m}$ is the moisture potential, $\mathrm{T}$ is temperature, $\mathrm{w}$ is the moisture content, $\alpha$ is the convective heat transfer coefficient, $\mathrm{B}$ is the convective moisture transfer coefficient, $\gamma$ is the Heat of adsorption or desorption, $\varepsilon$ is the Ratio of vapour diffusion coefficient to total moisture diffusion coefficient, $\delta$ is the Thermo-gradient coefficient, $\varphi$ is the Transformation function

In the resolution of the equations using Laplace transformations, dimensionless terms were introduced to equations 19-24 to change it to dimensionless form. Validation of the equations was done using the experimental set up in Figure 2. The porous material is a multilayer material whereby that one side is permeable and exposed to outdoor humid condition while the other side of the wall which is impermeable were subjected to cold temperature.

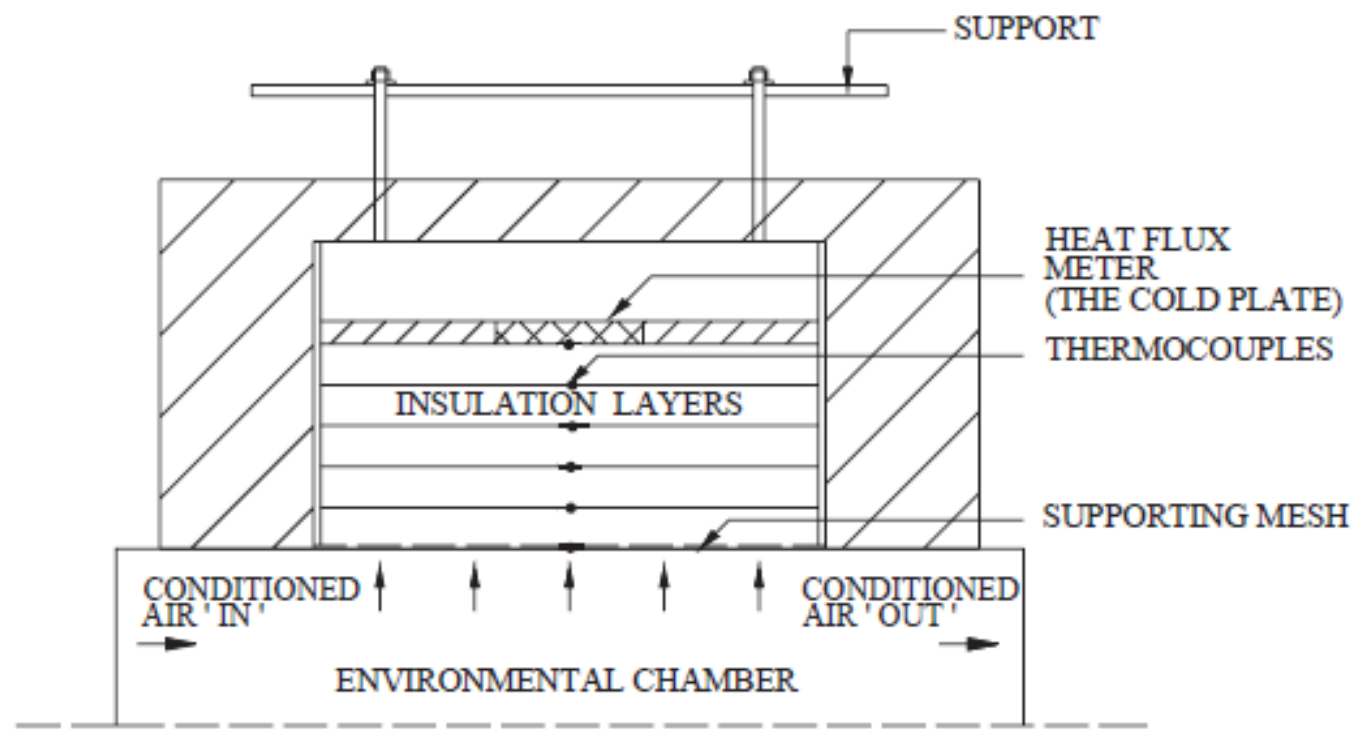

Figure 2: the experimental set of the testing rig for model evaluation $[45,54]$.

Validations of the numerical simulation model although showed the same trend with the experimental data but looking at Figure 3 plotted by the authors it shows that there is still temperature variations which imply that there is still some omitted parameters like hysteresis which is yet to be understood by researchers because of non-homogeneous nature of some porous materials, however, moisture profile was more accurately predicted as shown in Figure 4. 


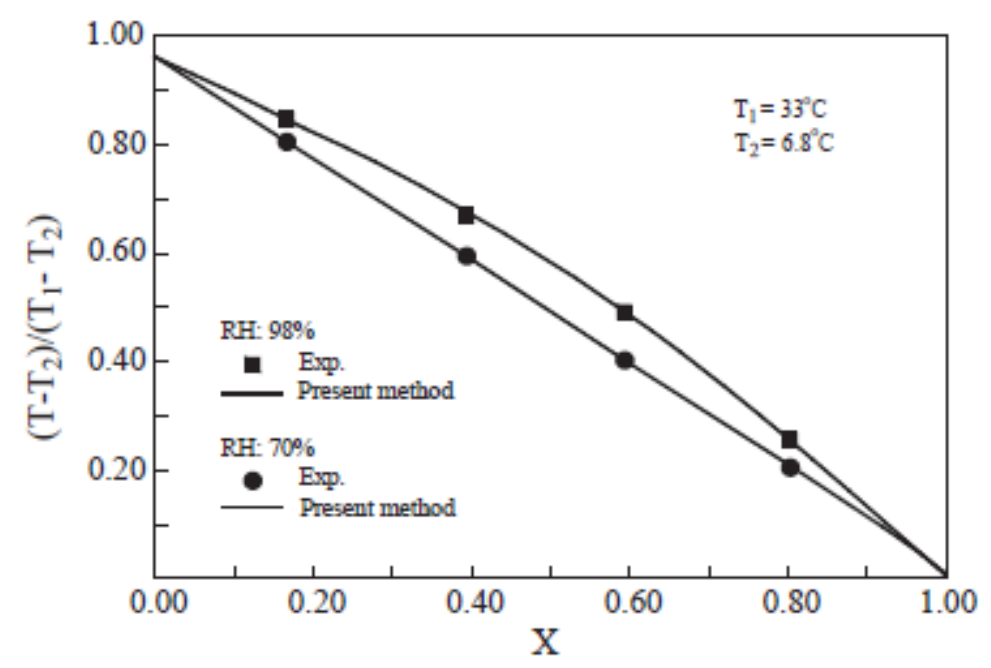

Figure 3: Comparison of the numerically simulated temperature profiles with the experimental result after quasi-steady state [51].

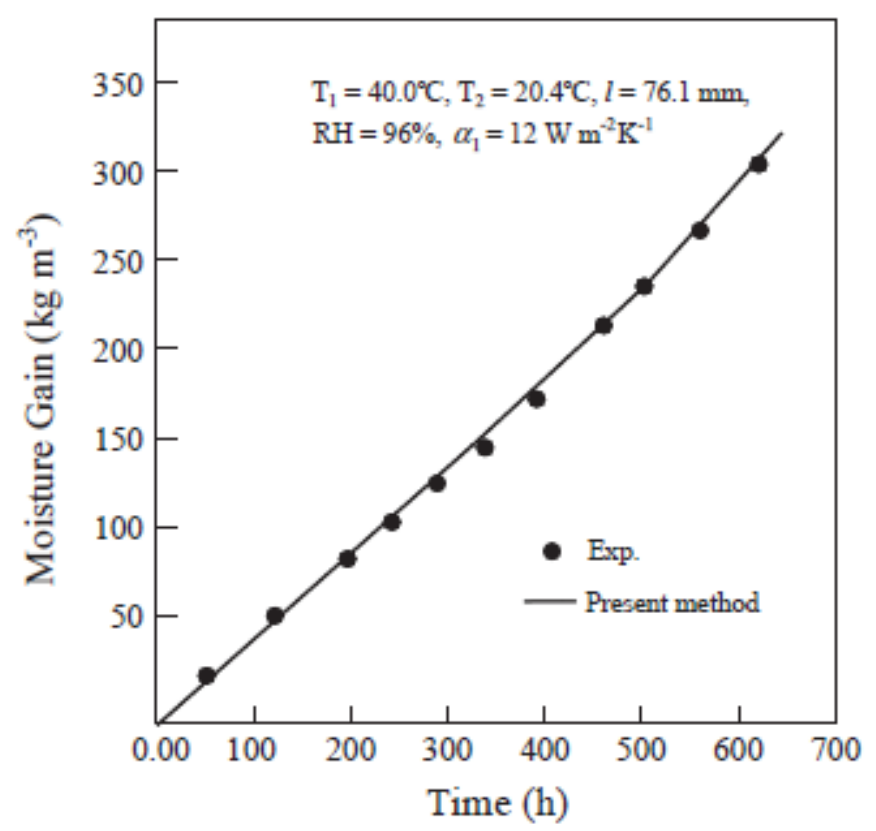

Figure 4: Comparison of predicted moisture gained with the experimental result [51].

Simo-Tagne et al [9] presented a numerical model for predicting the hygrothermal transfer for concrete wall for outdoor conditions in sub- Saharan Africa. The model took into account all kinds of bound and integrated the type of flow in the boundary conditions which is not common in other established models. They also stated that all water type occurring in the material is modified during the moisture transfer, therefore they presented the mass conservation equations for liquid water, bound water and vapour phases in equation 25-27 respectively as follows

$\frac{\partial\left(\alpha S \rho_{l}\right)}{\partial t}+\vec{\nabla} \cdot \vec{J}_{l}=-K_{l}$

Where $K_{1}$ is the volume mass flow rate of the conversion of the unbound water phase to vapour while $\vec{J}_{l}$ the flux vector of the liquid phase 
$\frac{\partial\left(X_{b} \rho_{S}\right)}{\partial t}+\vec{\nabla} \cdot \vec{J}_{a s}=-K_{a s}$

Where $\vec{J}_{\text {as }} \mathrm{Kl}$ and $\mathrm{Kas}$ the flux vector of the bound water phase and the volume mass flowrate to the conversion of bound water to unbound water are respectively. The Contribution of water vapour to the mass balance equations is given by:

$\frac{\partial\left(\alpha(1-S) \rho_{g} C_{g}\right)}{\partial t}+\vec{\nabla} \cdot\left(\rho_{g} \vec{V}_{g}+\vec{J}_{g}\right)=K_{a s}+K_{l}$

$\rho_{g} \vec{V}_{g}$ is the flux characteristic of the movement of the vapour phase.

Using equations 25-27, equation 28 was obtained.

$\frac{\partial\left(\rho_{S} H\right)}{\partial t}+\vec{\nabla} \cdot\left(\rho_{g} \vec{V}_{g}+\vec{J}_{l}+\vec{J}_{a s}+\vec{J}_{g}\right)=0$

The heat energy balance was given by equation 29 as follows

$\left[\rho \mathrm{C}_{\mathrm{p}} \frac{\partial \mathrm{T}}{\partial \mathrm{t}}+\overrightarrow{\nabla J}_{\mathrm{T}}\right]_{\mathrm{s}}+\left[\rho \mathrm{C}_{\mathrm{p}} \frac{\partial \mathrm{T}}{\partial \mathrm{t}}+\overrightarrow{\mathrm{V}} \cdot \vec{\nabla} \mathrm{T}\right]_{\mathrm{g}}+\left[\rho \mathrm{C}_{\mathrm{p}} \frac{\partial \mathrm{T}}{\partial \mathrm{t}}+\overrightarrow{\mathrm{V}} \cdot \overrightarrow{\nabla T}\right]_{\mathrm{l}}+\mathrm{K}_{\mathrm{l}} \mathrm{L}+\mathrm{K}_{\mathrm{as}}\left(\mathrm{L}+\mathrm{E}_{\mathrm{b}}\right)=0$

Where $\vec{V}_{g}, \vec{V}_{l}$ and $\vec{J}_{T}$ were kinetic of vapour, liquid phase and the heat conduction flux vector in the wood.

The boundary conditions for equations 35 and 36 are given in equations 30 and 31 as follows

$\left.\left[-\rho_{\mathrm{s}}\left(\mathrm{E}_{\mathrm{b}}+L\right) \mathrm{D}_{\mathrm{H}} \frac{\partial \mathrm{H}}{\partial \mathrm{x}}-\left(\lambda+\alpha_{\mathrm{t}} \rho_{\mathrm{s}}\left(\mathrm{E}_{\mathrm{b}}+\mathrm{L}\right) \mathrm{D}_{\mathrm{H}}\right) \frac{\partial \mathrm{T}}{\partial \mathrm{x}}\right]\right|_{\mathrm{x}=0}=\mathrm{h}_{\mathrm{c}, \text { ext }}\left(\mathrm{T}_{\text {aext }}-\mathrm{T}(0, \mathrm{t})\right)+$

$\rho_{\mathrm{w}} \mathrm{Lh}_{\mathrm{m}, \text { ext }}\left(\mathrm{X}_{\text {eq }}\left(\mathrm{T}_{\text {aext }}, \mathrm{HR}_{\text {aext }}\right)-\mathrm{H}(0, \mathrm{t})\right)+\mathrm{G}_{\text {gloi }}$

$\left.\left[-\mathrm{D}_{\mathrm{H}} \frac{\partial \mathrm{H}}{\partial \mathrm{x}}-\alpha_{\mathrm{t}} \mathrm{D}_{\mathrm{H}} \frac{\partial \mathrm{T}}{\partial \mathrm{x}}\right]\right|_{\mathrm{x}=0}=\mathrm{h}_{\mathrm{m}, \mathrm{ext}}\left(\mathrm{X}_{\mathrm{eq}}\left(\mathrm{T}_{\text {aext }}, \mathrm{HR}_{\text {aext }}\right)-\mathrm{H}(0, \mathrm{t})\right)$

The above equations were discretized with finite differences using the Crank-Nicolson scheme and the solution is with the Gauss-Seidel relaxation iteration method using Fortran 90 language. Validation of the model was with hemp concrete with a low mean relative error is shown in Figure 5 below.

\section{Hygrothermal transfer models for wooden walls}

The impact of wood as a building material for walls has been explored greatly in literature. The investigation has been carried out on the effects of woods on thermal comfort in terms of, relative humidity, temperature, background noise levels and $\mathrm{CO}_{2}$ concentrations [55-61]. Therefore wood is energy efficient with lower $\mathrm{CO}_{2}$ concentrations. Wood as a hygroscopic material absorbs moisture from the environment which has a direct and indirect impact on the room conditions and thermal comfort [62]. Therefore the type of wood, thickness, moisture isotherm etc. has been factored in the predictive models to describe the hygrothermal behaviour of wood for indoor and outdoor conditions. Due to the flexibility of Luikov models, it has formed the basis for modelling the coupled heat and mass transfer for porous material independent of hygroscopic nature. The model accounts for all the bonding water simplistically without restricting the water transfer mechanism [63]. Therefore these models can be applied for one, two or three dimensional coupled heats and mass transfer in woods. Younsi et al [63] used this model for predicting the temperature and moisture transfer in a wooden slab. After defining the entire dimensionless variables, they used the finite element method which operates in Matlab to solve the partial differential equations in three dimensions. They concluded that different dimensionless numbers (Luikov, Kossovitch, Posnov and Biot numbers) in the coupled heat and mass transfer equations affected the overall heat and mass transfer behaviour of 
wooden slab. Comparison of this model with analytical and experimental data showed closer agreement with the analytical model rather than experimental data. Osayintola et al. [26] used a combined Knudsen and Fickian diffusion and neglected thermal diffusion in the modelling heat and mass transfer evolution in spruce wood. The energy and mass conservation equations were defined in equations $32-35$ as follows:
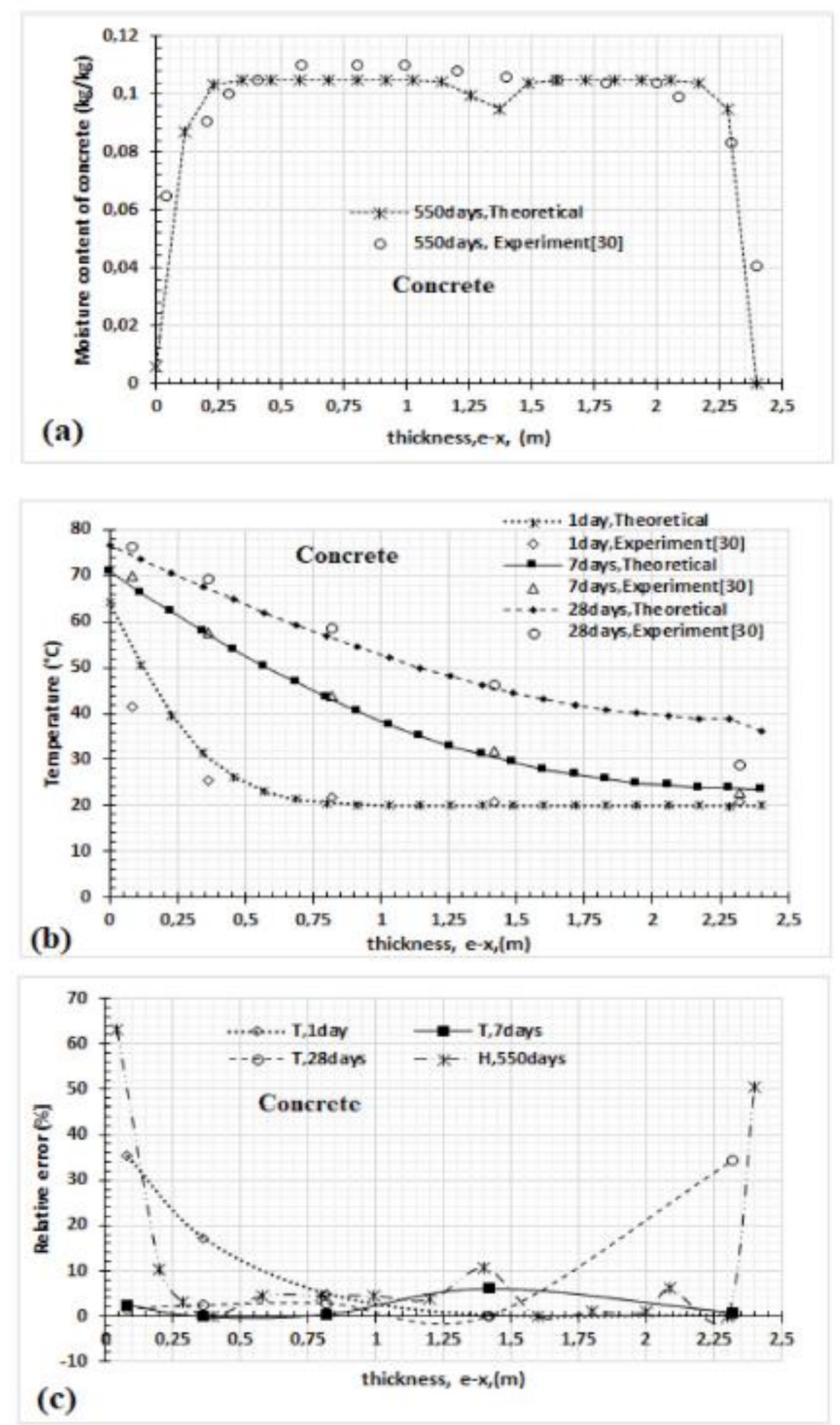

Figure 5. Comparison of experimental and simulated data (moisture content (a) and temperature (b)) through the wall thickness in concrete, and variations of the mean relative error (c) [9].

$\rho \ell \frac{\partial \varepsilon \ell}{\partial t}+\dot{m}=0$ 


$$
\begin{aligned}
& \frac{\partial\left(\rho_{v} \varepsilon_{g}\right)}{\partial t}-\dot{m}=\frac{\partial}{\partial x}\left(D_{\text {eff }} \frac{\partial \rho_{v}}{\partial x}\right) \\
& \rho C_{p e f f} \frac{\partial T}{\partial t}+\dot{m} h_{f g}=\frac{\partial}{\partial x}\left(k_{e f f} \frac{\partial \rho_{v}}{\partial x}\right) \\
& \dot{m}=-\rho 0 \frac{\partial u}{\partial t}
\end{aligned}
$$

Where $C_{\text {peff }}$ is the specific heat capacity at constant pressure $(J /(\mathrm{kg} \mathrm{K}))$, Deff is the effective vapour diffusion coefficient $\left(\mathrm{m}^{2} / \mathrm{s}\right), \mathrm{h} f \mathrm{~g}$ is the latent heat of vaporization/sorption $(\mathrm{J} / \mathrm{kg}), \varepsilon$ is the volume fraction, $\mathrm{Q}$ is the density $(\mathrm{kg} / \mathrm{m} 3)$, Qo dry density of the plywood specimen $\left(\mathrm{kg} / \mathrm{m}^{3}\right), \mathrm{m}^{\cdot}$ phase change rate per unit volume $\left(\mathrm{kg} /\left(\mathrm{m}^{3} \mathrm{~s}\right)\right)$ or mass flow rate $(\mathrm{kg} / \mathrm{s}), \mathrm{u}$ is the mass of moisture adsorbed per $\mathrm{kg}$ of dry spruce plywood $(\mathrm{kg} / \mathrm{kg}), \mathrm{x}$ distance from the top of plywood specimen $(\mathrm{m}), \mathrm{t}$ time $(\mathrm{s}), \mathrm{T}$ temperature $\left({ }^{\circ} \mathrm{C}\right)$

The above equations were discretely solved and a stable solution was provided with a relaxed, Gauss-Seidel iteration method. Discretization was by finite difference method with $2^{\text {nd }}$ order accuracy for the implicit scheme. Although the authors suggested that the presented diffusion model can be used to compare the experimental results and set benchmarks for similar materials but they did not show this with their experimental data. Rather they only fitted the sorption data with moisture content, thermal conductivity and water vapour permeability with good results. Figure 6 showed the fitting of the sorption data with a moisture content which is very good

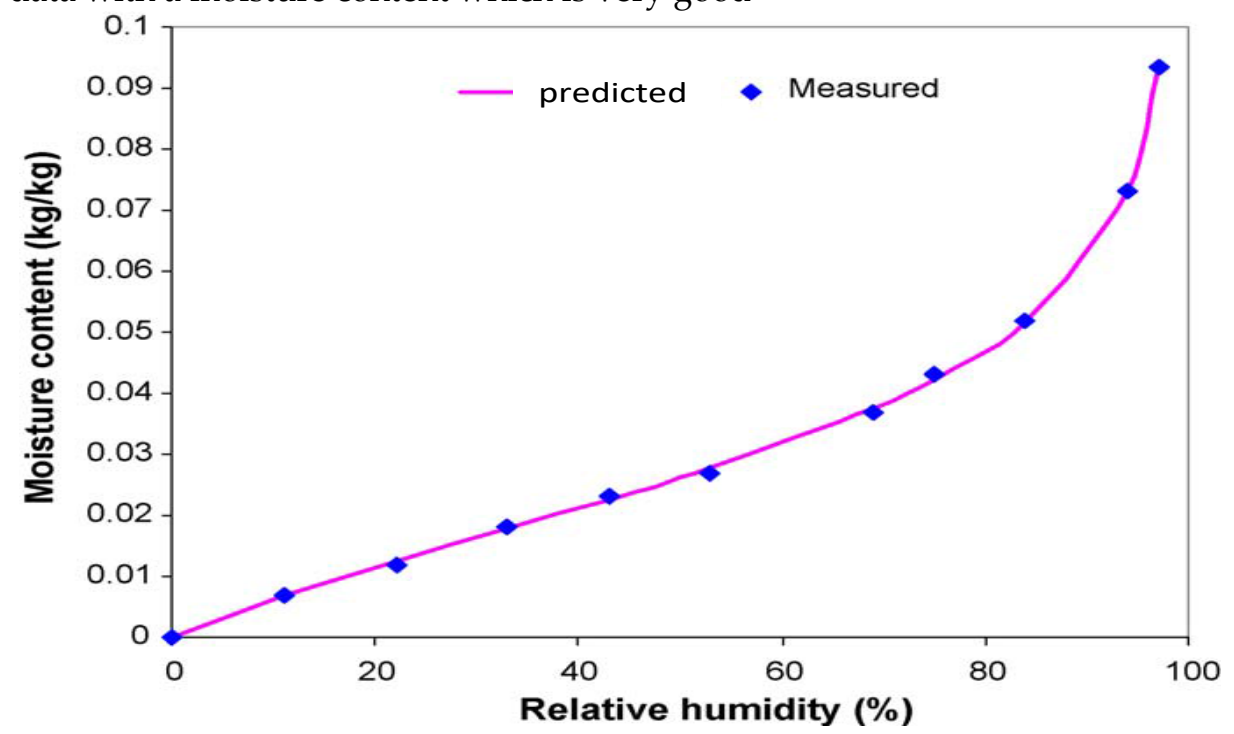

Figure 6: fitting of the Sorption isotherm for spruce plywood with moisture content data [26].

Simonson et al [64] presented a numerical simulation model to predict the moisture transfer (indoor climate) between the indoor air and the structural materials for wooden building in Belgium, Germany, Finland, and Italy. The model was developed to predict the temperature and relative humidity and applied to measure the comfort thresholds of the occupants in the building. The analysis of the model showed that the permeable interior layer is more satisfactory than when the interior layer is made with a water-resistant layer. The model is presented following the Ficks law of diffusion as follows $q M=-k d(u, T) \nabla p_{v}-\rho_{0} D_{w}(u, T) \nabla u+v_{a} \rho_{v}+K \rho_{w} g$

Where Pv partial pressure of water vapour $(\mathrm{Pa})$, @o dry density of the porous material $(\mathrm{kg} / \mathrm{m} 3)$, ov density of water vapour $\left(\mathrm{kg} / \mathrm{m}^{3}\right)$, ow density of liquid water $(\mathrm{kg} / \mathrm{m} 3), \mathrm{T}$ temperature $(\mathrm{C})$, u moisture content $(\mathrm{kg} / \mathrm{kg})$, va velocity of air $(\mathrm{m} / \mathrm{s})$, Dw liquid moisture diffusivity $\left(\mathrm{m}^{2} / \mathrm{s}\right), \mathrm{g}$ acceleration of gravity $\left(\mathrm{m} / \mathrm{s}^{2}\right), \mathrm{K}$ moisture permeability $(\mathrm{s})$, kd vapour permeability $(\mathrm{kg} / \mathrm{s} \mathrm{m} \mathrm{Pa)}$ 
Equation 36 is adopted from IEA ECBCS Annex 24 'Heat, Air and Moisture Transfer in Insulated Envelope Parts presented in detail in Hens [65]. The model took into consideration all the energy components of the moisture transfer process for adsorption, desorption, condensation, evaporation, freezing and thawing. The conservation equations were solved simultaneously to predict the variable indoor conditions under different experimental data obtained in the field [66- 71].

Talukdar et al [72] used a numerical model to set a benchmark for 1-D transient heat and moisture transfer models of spruce wood as a building material. Although the partial differential equations presented in equations 25-28 was used to set the governing energy conservation equations they used analytical approach to set the moisture penetration depth through the woods using equation 37 and 38. For a semi-porous material, the analytical equation developed for vapour transport is given in equation 30 as follows

$$
\frac{\left(\rho_{v}-\rho_{v i}\right)}{\left(\rho_{\infty}-\rho_{v i}\right)}=\operatorname{erfc}\left(\frac{x}{\sqrt[2]{\alpha_{m} e f f^{t}}}\right)-\left[\exp \left(\frac{D_{m} x}{D_{e f f}}+k \frac{h_{m}^{2} \alpha_{m} e f f^{t}}{D_{e f f}^{2}}\right)\right] \times\left[\operatorname{erfc}\left(\frac{x}{\sqrt[2]{\alpha_{m} e f f^{t}}}+\frac{h_{m} \sqrt{\alpha_{m} e f f^{t}}}{D_{e f f}}\right)\right]
$$

$\frac{\left(\rho_{v \delta_{m}}-\rho_{v i}\right)}{\left(\rho_{\infty}-\rho_{v i}\right)}=0.01$

Where Deff is the effective vapour diffusion coefficient $\left[\mathrm{m}^{2} / \mathrm{s}\right], \mathrm{hm}$ is the convective mass transfer coefficient $[\mathrm{m} / \mathrm{s}], \alpha_{\text {meff }}$ is the effective moisture diffusivity $\left[\mathrm{m}^{2} / \mathrm{s}\right]$, @ is the density $\left[\mathrm{kg} / \mathrm{m}^{3}\right], \mathrm{Q}_{0}$ is the dry density $\left[\mathrm{kg} / \mathrm{m}^{3}\right], \mathrm{x}$ is the distance from the top of the specimen $[\mathrm{m}]$ or $[\mathrm{mm}]$ when specified, $\boldsymbol{\delta}_{\boldsymbol{m}}$ is the vapour boundary layer thickness $[\mathrm{m}]$ or depth of moisture penetration.

Figure 7 showed the result of the model and the effect of moisture penetration, at a step change of relative humidity and varying airflow rates. The obtained results show that increasing the air velocity increases the temperature, relative humidity and moisture accumulation within the plywood.

Watt et al [73] proposed a two-dimension model for a light timber wall with an air barrier with changes in air tightness in a Swedish environment shown in figure 8 . The model was used to predict the moisture accumulation and mould growth within the building envelop. The magnitude of moisture accumulation is higher behind the outdoor air-tight layer of the simulated wall with the interior of the wall unsealed when compared to the sealed inside.

Simo-Tagne et al [9] numerical model presented in equations 25-31 above was also used to predict the hygrothermal transfer for different wooden wall for outdoor conditions in sub- Saharan Africa. In this case the model took into account the bound water present in wood with the integration of the flow patter in the boundary conditions. Validation of the model was with Norway Spruce wood with a low mean relative error is shown in Figure 9 below.

Further analysis of the model showed that less dense wood with increased thickness provided better thermal comfort. Therefore the nature of the wood and climatic factors is an important consideration that affects the hygrothermal transfer in woods.

Simo-Tagne et al [74] also presented a numerical simulation model for building walls in Nancy France. The same approach and solutions in Simo-Tagne et al [74] was adopted but they integrated the Dufour and Soret effect. The driving potential for the heat and mass transfer was temperature and moisture gradient. The model showed the negligible influence of the wooden structure while thickness is important in cancelling the effect of ambient conditions. 

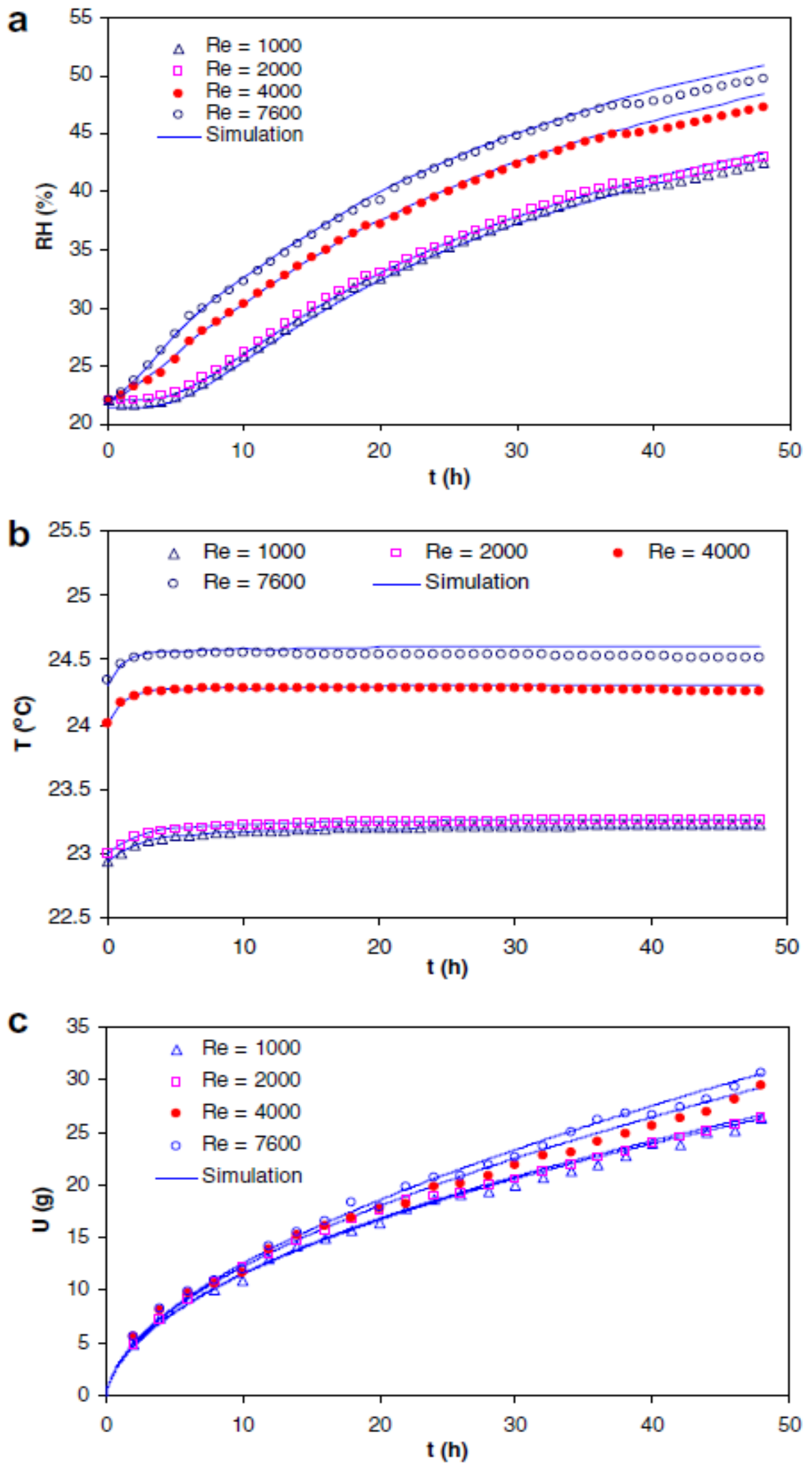

Figure 7: experimental and predicted (a) relative humidity, (b) temperature and (c) moisture accumulation inside the plywood at a plywood thickness of $9 \mathrm{~mm}$ and at a $50 \%$ relative humidity step change and at varying air flow rates [72]. 


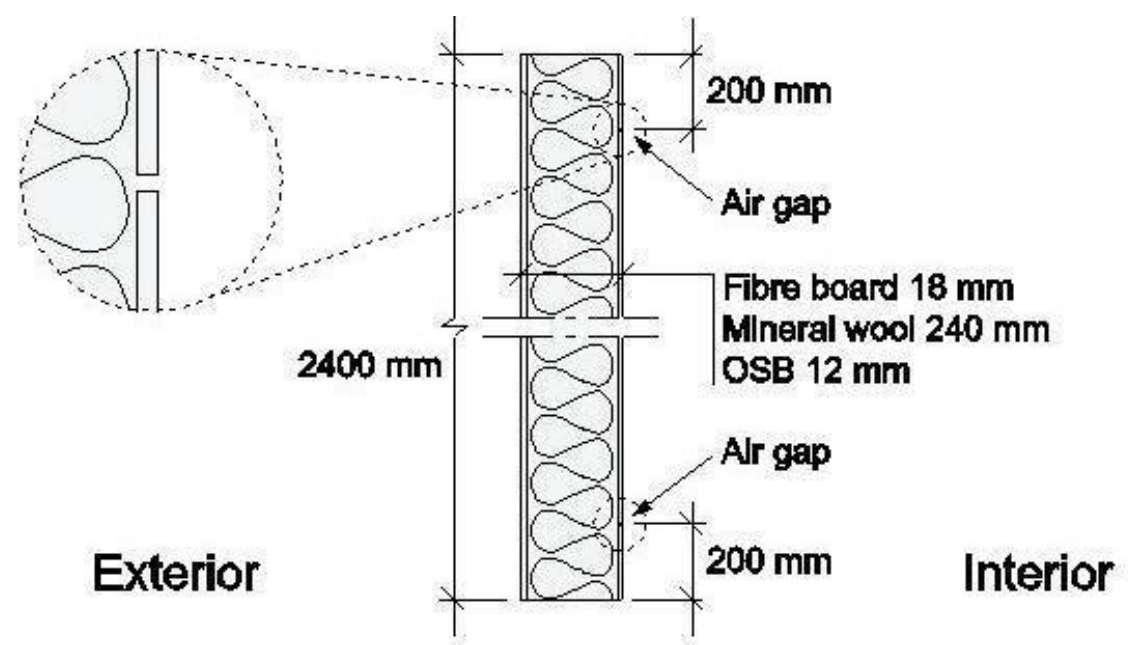

Figure 8: Simulated wall with air gaps [73]
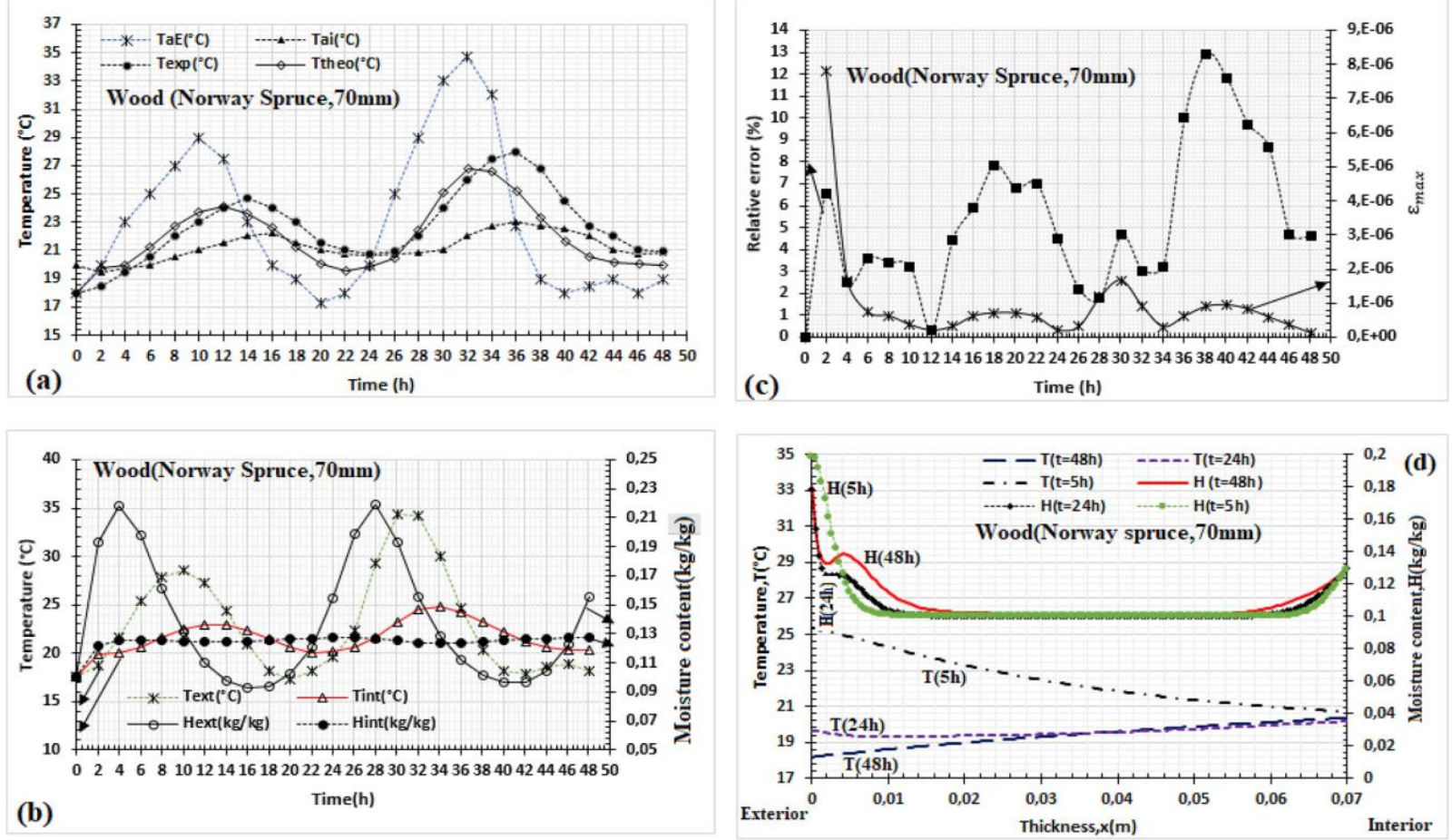

Figure 9: (a) The comparison of the measured temperature variations and predicted temperature variations in the Norway Spruce wood wall thickness(c) showed the mean relative error generated (b. d). The changes in the temperatures and moisture contents respectively at the wood surfaces of the wall [9].

Berger et al. [75] proposed a numerical model using Scharfetter-Gummel sheme combined with a two-step Runge-Kutta approach. Three phases were distinguished: water vapor, liquid water and dry air. The moisture mass balance was given as follow:

$\left\{\begin{array}{c}\frac{\partial}{\partial \mathrm{t}}\left(\mathrm{w}_{\mathrm{v}}+\mathrm{w}_{\mathrm{l}}\right)=-\nabla \cdot\left(\mathrm{J}_{\mathrm{c}, \mathrm{v}}+\mathrm{J}_{\mathrm{c}, \mathrm{l}}\right) \\ \frac{\partial}{\partial \mathrm{t}}\left(\mathrm{w}_{\mathrm{v}}+\mathrm{w}_{\mathrm{da}}\right)=-\nabla \cdot\left(\mathrm{J}_{\mathrm{c}, \mathrm{v}}+\mathrm{J}_{\mathrm{c}, \mathrm{da}}\right)+\mathrm{l}_{\mathrm{c}, \mathrm{v}}\end{array}\right.$

The energy balance was given as follow:

$\left(\mathrm{c}_{\mathrm{o}} \rho_{\mathrm{o}}+\mathrm{C}_{\mathrm{v}} \mathrm{w}_{\mathrm{v}}+\mathrm{C}_{\mathrm{l}} \mathrm{w}_{\mathrm{l}}+\mathrm{C}_{\mathrm{da}} \mathrm{w}_{\mathrm{da}}\right) \frac{\partial \mathrm{T}}{\partial \mathrm{t}}=-\nabla \cdot \mathrm{J}_{\mathrm{q}}-\mathrm{r}_{\mathrm{vl}} \mathrm{l}_{\mathrm{c}, \mathrm{v}}-\nabla \cdot\left(\mathrm{C}_{\mathrm{v}} \mathrm{T}\right) \mathrm{J}_{\mathrm{c}, \mathrm{v}}-\nabla \cdot\left(\mathrm{C}_{\mathrm{l}} \mathrm{T}\right) \mathrm{J}_{\mathrm{c}, \mathrm{l}}-$

$\nabla \cdot\left(\mathrm{C}_{\mathrm{da}} \mathrm{T}\right) \mathrm{J}_{\mathrm{c}, \mathrm{da}}$

Where the volumetric vapour source $\mathbf{l}_{\mathbf{c}, \mathbf{v}}$ is given by:

$\mathrm{l}_{\mathrm{c}, \mathrm{v}}=\frac{\Pi(1-\sigma) \mathrm{P}_{\mathrm{v}}}{\mathrm{R}_{\mathrm{v}} \mathrm{T}^{2}} \frac{\partial \mathrm{T}}{\partial \mathrm{t}}+-\nabla \cdot \mathrm{J}_{\mathrm{c}, \mathrm{v}}$

The heat flux was expressed as: 
$\mathrm{J}_{\mathrm{q}}=-\lambda_{q} \nabla \mathrm{T}+\left(\mathrm{C}_{\mathrm{v}} \mathrm{w}_{\mathrm{v}}+\mathrm{C}_{\mathrm{da}} \mathrm{w}_{\mathrm{da}}\right) \frac{\mathrm{T}}{\Pi(1-\sigma)} V$

$\mathrm{V}$ is the vapour velocity taken equals to the air velocity and given by:

$V=-\frac{k_{v d a}}{\mu} \nabla \mathrm{P}$

The flux of water vapour was given by:

$\mathrm{J}_{\mathrm{c}, \mathrm{v}}=-k_{v} \nabla \mathrm{P}_{v}+\frac{\mathrm{P}_{v}}{\mathrm{R}_{\mathrm{v}} \mathrm{T}} V$

The flux of dry air was given by:

$\mathrm{J}_{\mathrm{c}, \mathrm{da}}=\frac{\mathrm{w}_{\mathrm{v}}+\mathrm{w}_{\mathrm{da}}}{\Pi(1-\sigma)} V-\mathrm{J}_{\mathrm{c}, \mathrm{v}}$

The flux of liquid water was given by:

$\mathrm{J}_{\mathrm{c}, \mathrm{I}}=-k_{m} \nabla \mathrm{P}_{v}+\frac{\mathrm{P}_{v}}{\mathrm{R}_{\mathrm{v}} \mathrm{T}} V-\mathrm{J}_{\mathrm{c}, \mathrm{v}}$

$k_{m}$ is the global moisture permeability, $\Pi$ is the porosity of the material, Indexes $\mathrm{V}$, 1 and da denote respectively water vapour, water liquid and dry air, $\mathrm{P}$ is the pressure, $\mathrm{w}$ is the volumetric concentration, $\mathrm{R}$ is the specie gas constant, $\mathrm{k}$ is the permeability, $\sigma$ is the saturation rate, $\mathrm{T}$ is the temperature, $\mathrm{C}$ is the specific heat, $\lambda_{q}$ is the thermal conductivity of the material, $r_{v l}$ is the latent heat of vaporization, $t$ is the time, $c_{0}$ is the specific heat, $\rho_{\mathrm{o}}$ is the dry-basis specific mass and $\nabla$ is the gradient symbol.

Applying this model to the wood fiber using the constant properties (without influences of humidity and temperature), Berger et al. [75] used a programme translated with Matlab ${ }^{\mathrm{TM}}$ to obtained the curves that defined well the experimental data presented in Figure 10.

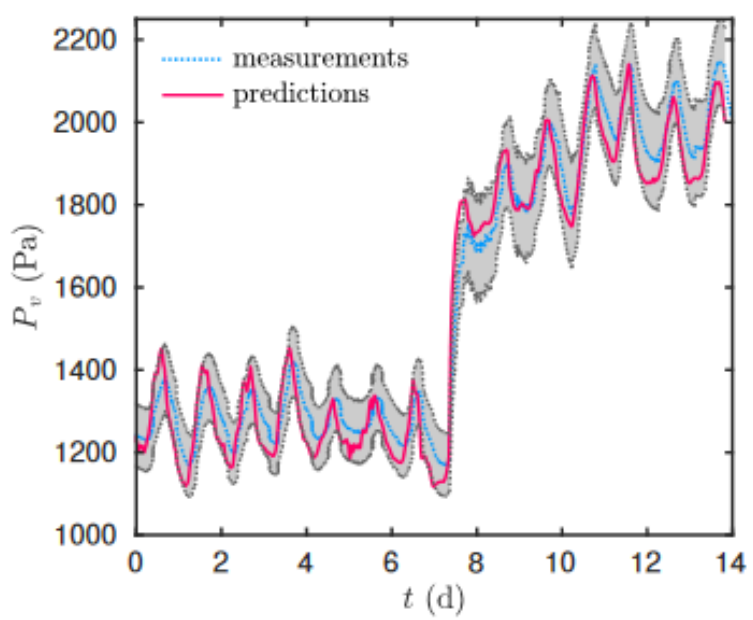

(a) $x=4 \mathrm{~cm}$

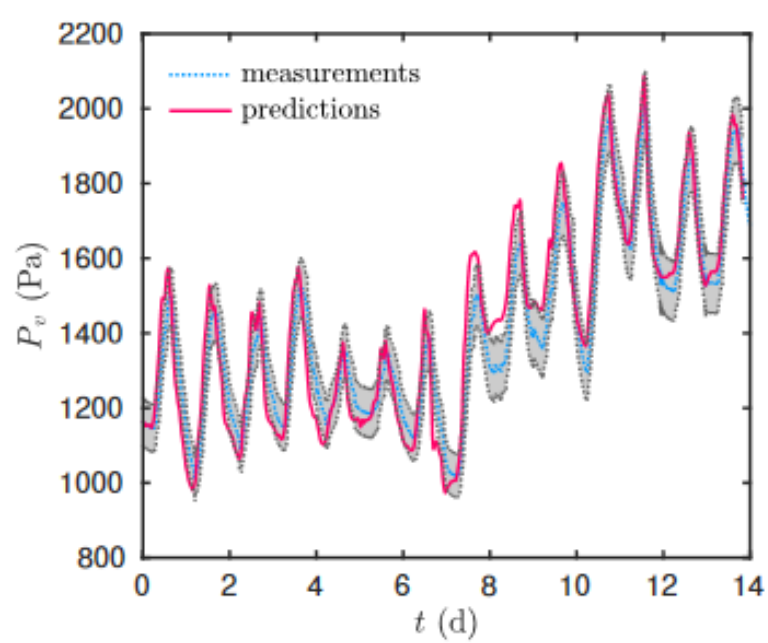

(c) $x=8 \mathrm{~cm}$

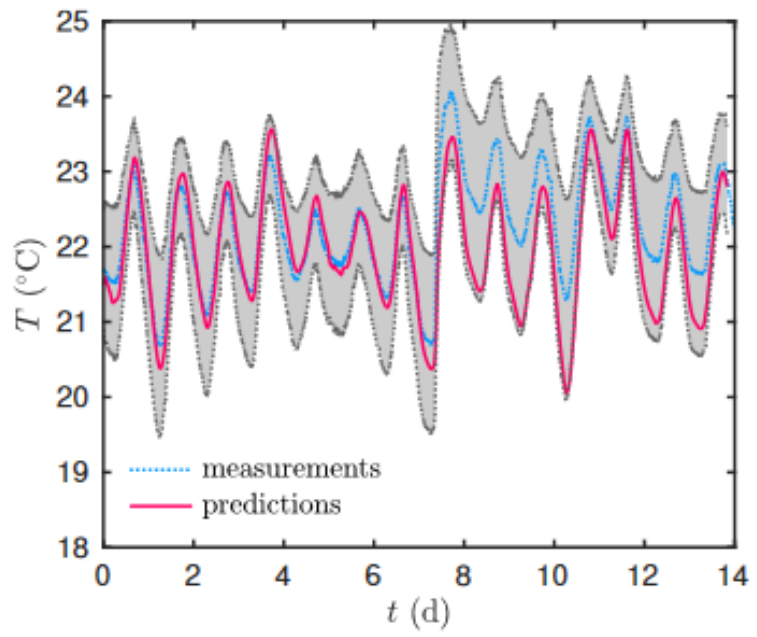

(b) $x=4 \mathrm{~cm}$

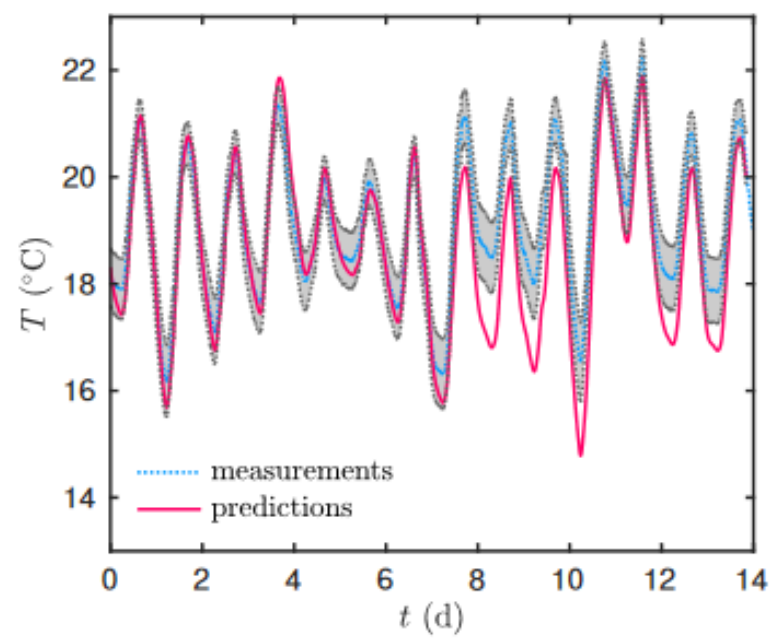

(d) $x=8 \mathrm{~cm}$ 


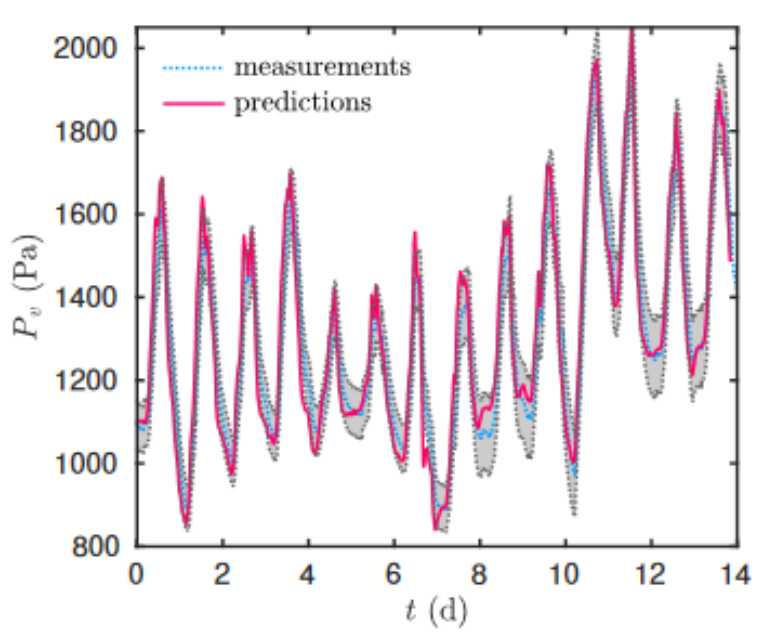

(e) $x=12 \mathrm{~cm}$

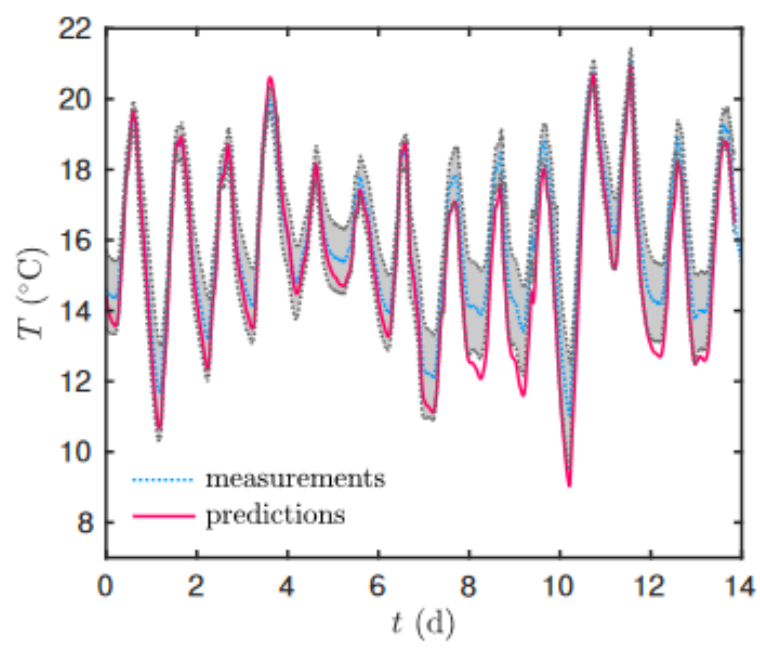

(f) $x=12 \mathrm{~cm}$

Figure 10: Comparison of the experimental and numerical results for vapor pressure (a, c, e) and temperature $(b, d, f)$. The grey shadows represent the measurement uncertainties [75].

Simo-Tagne et al. [76, 77] present a novel model of heat mass transfer through the wooden material. The model based initially of the description of each type of water (bound water, vapour and free water), equations obtained are given by:

$\left\{\begin{array}{c}\frac{\partial \mathrm{W}}{\partial \mathrm{t}}=\frac{\partial}{\partial \mathrm{x}}\left(\mathrm{D}_{\mathrm{HH}} \frac{\partial \mathrm{W}}{\partial \mathrm{x}}+\mathrm{D}_{\mathrm{HT}} \frac{\partial \mathrm{T}}{\partial \mathrm{x}}\right) \\ \rho \mathrm{C} \frac{\partial \mathrm{T}}{\partial \mathrm{t}}=\frac{\partial}{\partial \mathrm{x}}\left(\mathrm{D}_{\mathrm{TH}} \frac{\partial \mathrm{W}}{\partial \mathrm{x}}+\left(\lambda+\mathrm{D}_{\mathrm{TT}}\right) \frac{\partial \mathrm{T}}{\partial \mathrm{x}}\right)\end{array}\right.$

With:

$$
\begin{aligned}
& \mathrm{D}_{\mathrm{HH}}=\mathrm{D}_{\mathrm{H}}-\frac{\rho_{\mathrm{l}} \mathrm{k}}{\rho_{\mathrm{s}}}\left(\frac{\mathrm{k}_{\mathrm{r}}}{\mu}\right)_{1} \frac{\partial \mathrm{P}_{\mathrm{c}}}{\partial \mathrm{W}}+\frac{\rho_{\mathrm{g}} \mathrm{D}_{\mathrm{g}}}{\rho_{\mathrm{s}}\left(1-\mathrm{C}_{\mathrm{g}}\right)} \frac{\partial \mathrm{C}_{\mathrm{g}}}{\partial \mathrm{W}} \\
& \mathrm{D}_{\mathrm{HT}}=\mathrm{D}_{\mathrm{T}}-\frac{\rho_{\mathrm{l}} \mathrm{k}}{\rho_{\mathrm{s}}}\left(\frac{\mathrm{k}_{\mathrm{r}}}{\mu}\right)_{1} \frac{\partial \mathrm{P}_{\mathrm{c}}}{\partial \mathrm{T}}+\frac{\rho_{\mathrm{g}} \mathrm{D}_{\mathrm{g}}}{\rho_{\mathrm{s}}\left(1-\mathrm{C}_{\mathrm{g}}\right)} \frac{\partial \mathrm{C}_{\mathrm{g}}}{\partial \mathrm{T}} \\
& \mathrm{D}_{\mathrm{TT}}=\frac{(\mathrm{E}+\mathrm{L}) \rho_{\mathrm{g}} \mathrm{D}_{\mathrm{g}}}{1-\mathrm{C}_{\mathrm{g}}} \frac{\partial \mathrm{C}_{\mathrm{g}}}{\partial \mathrm{T}}-\mathrm{E} \rho_{\mathrm{l}} \mathrm{k}\left(\frac{\mathrm{k}_{\mathrm{r}}}{\mu}\right)_{1} \frac{\partial \mathrm{P}_{\mathrm{c}}}{\partial \mathrm{T}} \\
& \mathrm{D}_{\mathrm{TH}}=\frac{(\mathrm{E}+\mathrm{L}) \rho_{\mathrm{g}} \mathrm{D}_{\mathrm{g}}}{1-\mathrm{C}_{\mathrm{g}}} \frac{\partial \mathrm{C}_{\mathrm{g}}}{\partial \mathrm{W}}-\mathrm{E} \rho_{\mathrm{l}} \mathrm{k}\left(\frac{\mathrm{k}_{\mathrm{r}}}{\mu}\right)_{1} \frac{\partial \mathrm{P}_{\mathrm{c}}}{\partial \mathrm{W}} \\
& \mathrm{D}_{\mathrm{T}}=\frac{\mathrm{E}_{\mathrm{b}} \mathrm{HR}}{\mathrm{RT}^{2}} \frac{\partial \mathrm{X}_{\mathrm{e}}}{\partial \mathrm{HR}} \mathrm{D}_{\mathrm{H}}
\end{aligned}
$$

If $\mathrm{x}=0$, thus:

$\frac{\partial \mathrm{W}}{\partial \mathrm{x}}=0 ; \frac{\partial \mathrm{T}}{\partial \mathrm{x}}=0$

If $x= \pm e / 2$, thus:

$-\mathrm{D}_{\mathrm{HH}} \frac{\partial \mathrm{W}}{\partial \mathrm{x}}=\mathrm{h}_{\mathrm{m}}\left(\mathrm{W}-\mathrm{X}_{\mathrm{e}}\right)$

$-\left(\lambda+D_{\text {TT }}\right) \frac{\partial T}{\partial x}=h_{c}\left(T-T_{\text {air }}\right)+\rho_{\mathrm{s}} L D_{H H} \frac{\partial W}{\partial x}$

The thermal and hydric diffusivities ( pressure $\left(\mathrm{P}_{\mathrm{c}}\right)$; air permeability $\left(\mathrm{k}, \mathrm{k}_{\mathrm{r}}\right)$; diffusivity of the vapor in air drying $\left(\mathrm{D}_{\mathrm{g}}\right)$; concentration of the vapour $\left(\mathrm{C}_{\mathrm{g}}\right)$; densities of drying drying $\left(\rho_{\mathrm{g}}\right)$, free water $\left(\rho_{\mathrm{l}}\right)$ and dry wood $\left(\rho_{\mathrm{s}}\right)$; dynamical viscosity of the air drying $(\mu)$; mass diffusivity of wood material $\left(D_{H}\right)$; heat of vaporization $\left(\mathrm{E}, \mathrm{E}_{\mathrm{b}}\right)$; heat of sorption $(\mathrm{L})$; the sorption isotherm $\left(\mathrm{X}_{\mathrm{e}}\right)$ and relative humidity of drying air (HR); with R the gas perfect constant; e is the thickness, $h_{c}$ and $h_{m}$ are the heat and mass convective transfer coefficients respectively.

Using the real variations in thermophysical parameters presented in equations 4755, Simo-Tagne et al. [77] showed that the model is flexible and will allow to take into account all properties of the wood types and the movement of all types of water (bound 
water, free water, vapor of water). However they suggested that to adopt the model, the hydric diffusivities has to be experimentally determined for each wood.

Generally, to have accurate model for all the heat and mass transfer model equations, the sorption and desorption isotherm for all the materials have to be accurately determined and also the accurate boundary condition defined [77-79]. This values and equations mainly differentiated most of the presented equations in this reviewed with each other.

\section{Conclusions}

The hygrothermal transfer equations for various building walls are reviewed in this paper. The hygrothermal transfer is very important for the design of a building envelop for thermal comfort and economic and energy analysis of the building. Several numbers of energy and mass conservation equations with different boundary conditions and input considerations have been presented in this paper for soil-based and the wooden building wall. Most of the research ignored the effect of hysteresis in their models while very few considered the flow pattern of fluid through the wall surfaces. A review of the literature shows that most of the models were based on Luikov equations for heat and mass transfer and solution were mostly by finite difference methods. Validations of the models showed the influence of wall, thickness, the density of the material and climatic variations on the temperature and moisture evolutions within the building materials. The choice of building material in the building envelop has shown to influence the energy utilization in the building. However, literature, presenting imaging models using software like COMSOL multi-physics, CFD etc. is scarce bearing in mind that microscopic imagery is now deployed to measure the heat and moisture evolution in materials. Future models should include shrinkage or expansion influence especially in fibrous material like wood as they respond to ambient variations.

Author Contributions: Conceptualization, M.C.N.; methodology, M.C.N; validation, M.C.N, M.S-T, I.E.E, M.I.I, M.A.A, F.I.A, R.K.; investigation, M.C.N, M.S-T, I.E.E, M.I.I, M.A.A, F.I.A, R.K; resources, M.C.N, M.S-T; data curation, M.C.N, M.S-T; writing - original draft preparation, M. C. N..; writing - review and editing, M.C N, M.S-T, I.E.E, M.I.I, M.A.A, F.I.A, R.K. All authors have read and agreed to the published version of the manuscript.

Funding: This research received no external funding

Data availability statement: Not applicable

Acknowledgement: Not applicable

Conflicts of Interest: The authors declare no conflict of interest.

\section{References}

1. Jang, M.; Hong, T.; Ji, C. Hybrid LCA model for assessing the embodied environmental impacts of buildings in South Korea. Environmental Impact Assessment Review 2015, 50, 143-155.

2. ONU-environnement, Vers un secteur des bâtiments et de la construction a emission zero, efficace, et resilient, Bilan mondial, 2017, 48, pp 2017.

3. Akata, A.M.E.A.; Njomo, D.; Agrawal, B. Assessment of building integrated photovoltaic (BIPV) for sustainable energy performance in tropical regions of Cameroon. Renew. Sustain. Energy Rev. 2017, 80, 1138-1152.

4. Chang, Y.; Ries, R.J.; Wang, Y. Life-cycle energy of residential buildings in China. Energy Policy 2013, 62, 656-664. http://dx.doi.org/10.1016/j.enpol.2013.07.053.

5. Sartori, I.; Hestnes, A.G. Energy use in the life cycle of conventional and low-energy buildings: a review article. Energy Build 2007, 39(3), 249-57. http://dx.doi.org/10.1016/j.enbuild.2006.07.001. 
6. El-dessouky, H.T.; Ettouney, H.M.; Bouhamra, W. A novel air conditioning system membrane air drying and evaporative cooling. Trans IChemE (Part A) 2000, 78, 999-1009.

7. Ndukwu , M.C.; Manuwa, S.I.; Bennamoun, L.; Olukunle, O.J.; $\cdot$ Abam, F.I. In-situ evolution of heat and mass transfer phenomena and evaporative water losses of three agro-waste evaporative cooling pads: an experimental and modeling study. Waste and Biomass Valorization 2019, 10, 3185-3195.

8. Braungardt, S.; Burger, V.; Zieger, J.; Kenkmann, T. Contribution of renewable cooling to the renewable energy target of the EU, Netherlands Enterprise Agency, July 2018 Publication number: RVO-088-1801/RP-DUZA (59p).

9. Simo-Tagne, M. ; Ndukwu, M.C. ; Rogaume, Y. Modelling and numerical simulation of hygrothermal transfer through a building wall for locations subjected to outdoor conditions in Sub-Saharan Africa. Journal of Building Engineering 2019, 26, 100901.

10. Hong, T.; Ji, C.; Park, H. Integrated model for assessing the cost and $\mathrm{CO}_{2}$ emission (IMACC) for sustainable structural design in ready-mix concrete. J Environ Manage 2012, 103, 1-8. http://dx.doi.org/10.1016/j.jenvman.2012.02.034.

11. Hong, T.; Ji, C.; Jang, M.; Park, H. Assessment model for energy consumption and greenhouse gas emissions during the construction phase. J Manag Eng 2013, 30(2), 226-235. http://dx.doi.org/10.1061/(ASCE)ME.1943-5479.0000199.

12. European Commission, Feuille de route pour une Europe efficace dans l'utilisation des ressources, (2011), p. 31pp.

13. Benahmed, L. ; Ben-Mostefa, F.Z. ; Integration d'un systeme de rafraichissement solaire au bâtiment. Faisabilite technicoeconomique, Master Thesis University of Abou Baker Belkaid Tlemcem (Algeria), 2013, p. 103.

14. Shin, S.; Tae, S.; Woo, J.; Roh, S. The development of environmental load evaluation system of a standard Korean apartment house. Renew Sust Energ Rev 2011,15(2), 1239-1249. http://dx.doi.org/10.1016/j.rser.2010.09.036.

15. Tae, S.; Shin, S.; Woo, J.; Roh, S. The development of apartment house life cycle $\mathrm{CO}_{2}$ simple assessment system using standard apartment houses of South Korea. Renew Sust Energ Rev 2011, 15(3), 1454-67. http://dx.doi.org/10.1016/j.rser.2010.09.053.

16. James, C.; Simonson, C.J.; Talukdar, P.; Roels, S. Numerical and experimental dataset for benchmarking hygroscopic buffering models. International Journal of Heat and Mass Transfer 2010, 53, 3638-3654.

17. Lelievre, D.; Colinart, T.; Glouannec, P. Hygrothermal behavior of bio-based building materials including hysteresis effects: experimental and numerical analyses. Energy and Buildings 2014, 84, 617-627.

18. Taylor, P.; Fuller, R.J.; Luther, M.B. Energy use and thermal comfort in a rammed earth office building. Energy Build. 2008, 40, 793-800.

19. Damfeu, J.C.; Meukam, P.; Jannot, Y. Modeling and estimation of the thermal properties of clusters aggregates for construction materials: the case of clusters aggregates of lateritic soil, sand, and pouzzolan. Int. J. Heat Mass Transf. 2016, 102, 407416.

20. Xingguo, G.; Youming, C.; Yongqiang, D. Development and experimental validation of a one-dimensional dynamic hygrothermal modeling based on air humidity ratio. J. Cent. South Univ. 2012, 19, 703-708.

21. Rafidiarison, H.M. ; Etudes expérimentales des transferts de masse et de chaleur dans les parois des constructions en bois en vue de leur modélisation, Application aux économies d'énergies et au confort dans l'habitat, Doctorat thesis, Lorraine University, 2012, 204p.

22. Simpson, W.; TenWolde, A. Physical Properties and Moisture Relations of Wood, Chapter 3, Forest Products Laboratory, 1999, p. $4633.1-3.25$.

23. Jafarian, H.; Demers-Claude, M.H.; Blanchet, P.; Laundry, V. Impact of indoor use of wood on the quality of interior ambiances under overcast and clear skies: case study of the Eugene H. Kruger building, Quebec City. BioResources 2016, 11 (1), 1647-1663.

24. Watchman, M.; Potvin, A.; Demers-Claude, M.H. Wood, and comfort: a comparative case study of two multifunctional rooms, BioResources 2017, 12 (1), 168-182.

25. Pajchrowski, G.; Noskowiak, A.; Lewandowska, A.; Strykowski, W. Wood as a building material in the light of environmental assessment of full life cycle of four buildings. Constr. Build. Mater. 2014, 52, 428-436.

26. Osanyintola, O.F.; Simonson, C.J. Moisture buffering capacity of hygroscopic building materials: experimental facilities and energy impact. Energy and Building 2006, 38, 1270-1282.

27. Bevan, R.; Woolley, T. Hemp Lime Construction: A Guide to Building with Hemp Lime Composites, IHS/BRE Press, Bracknell, Berkshire, UK, 2008.

28. Woolley, T.; Thompson, H.; McGrogan, T.; Alexander, M. The role of low impact building materials in sustainable construction: the potential for hemp, in: Proceeding of Sustainable Building Conference, 13-18 September 2004, Stellenbosch, South Africa, 2004.

29. Pierre, T.; Colinart, T.; Glouannec, P. Measurement of thermal properties of biosourced building materials. International Journal of Thermophysics 2013. http://dx.doi.org/10.1007/s10765-013-1477-0.

30. Prétot, S.; Collet, F.; Garnier, C. Life cycle assessment of a hemp concrete wall: impact of thickness and coating. Building and Environment 2013, 71, 223-231.

31. Hildebrandt, J.; Hagemann, N.; Thran, D. The contribution of wood-based construction materials for leveraging a low carbon building sector in Europe. Sustainable Cities and Society 2017, 34, 405-418.

32. Le Dreau, J.; Heiselberg, P.; Lund, R.J. A full-scale experimental set-up for assessing the energy performance of radiant wall and active chilled beam for cooling buildings. BUILD SIMUL 2014, 1-13. https://doi.org/10.1007/s12273-014-0190-7.

33. Busser, T; Piot, A.; Pailha, M.; Rouchier, S.; Woloszyn, M. Experimental and numerical study of wood-based materials: from material to room scale. Energy Procedia 2017, 132, 747-752. 
34. Simo-Tagne, M. ; Zoulalian, A. ; Rogaume, Y. ; Rémond, R. ; Bonoma, B. Modélisation des isothermes de sorption, caractérisation des propriétés thermodynamiques et détermination des humidités d'équilibre d'usage des bois tropicaux. Revue des Energies Renouvelables, 2016, 19(1), 79-96.

35. Chen, D.P.; Qian, C.X.; Liu, C.L. A numerical simulation approach to calculating hygrothermal deformation of concrete based on heat and moisture transfer in porous medium. International Journal of Civil Engineering 2010, 8 (4), $287-291$.

36. Ruuska, A.; Hakkinen, T. Efficiency in the delivery of multi-storey timber buildings. Energy Procedia 2016, 96, $190-201$.

37. Simo Tagne, M. ; Bonoma, B. ; Njomo, D. Modélisation du séchage convectif et symétrique des bois d'ayous, d'eucalyptus grandis et d'ébène, simulation numérique et validation expérimentale. Afrique science 2011, 7(03), 15-32.

38. Mendes, N.; Philippi, P.C. A method for predicting heat and moisture transfer through multilayered walls based on temperature and moisture content gradients. Int. J. Heat Mass Transf. 2005, 48, 37-51.

39. Pasztory, Z.; Peralta, P.N.; Molnar, S.; Peszlen, I. Modeling the hygrothermal performance of selected North American and comparable European wood-frame house walls. Energy Build. 2012, 49, 142-147.

40. Bing, Z.; Zhongqing, C.; Liang, Z. Numerical simulation for coupled heat and moisture transfer in building material, 3rd International Conference on Material, Mechanical and Manufacturing Engineering (IC3ME, 2015, pp. $216-221$.

41. Holm, A.; Kunzel-Hartwig, M.; Non-isothermal moisture transfer in porous building materials, Materialsweek, Munich, 2000, pp. 1-9 https://www.ibp.fraunhofer.de/ content/dam/ibp/de/documents/non-isothermal_tcm45-35019.pdf , Accessed date:18 August 2018.

42. Djongyang, N.; Tchinda, R.; Njomo, D. A study of coupled heat and mass transfer across a porous building component in intertropical conditions. Energy Build. 2009, 41, 461-469.

43. Tran Le, A.D.; Samri, D.; Rahim, M.; Douzane, O.; Promis, G.; Langlet, T. Effect of temperature-dependent sorption characteristics on the hygrothermal behavior of hemp concrete. Energy Procedia 2015,78, 1449-1454.

44. Bonefacic, I.; Wolf, I.; Frankovic, B. Numerical modeling of thermal comfort conditions in an indoor space with solar radiation sources. J. Mech. Eng. 2015, 61 (11), 641-650.

45. Menghao, Q.; Belarbi, R.; Ait-Mokhtar, A.; Seigneurin, A. An analytical method to calculate the coupled heat and moisture transfer in building materials. Int. Commun. Heat Mass Transf. 2006, 33, 39-48.

46. Kwiatkowski, J.; Woloszyn, M.; Roux, J.J. Modelling of hysteresis influence on mass transfer in building materials. Building and Environment 2009, 44, 633-642.

47. Steeman, H.; Van Belleghem, M.; Janssens, A.; De Paepe, M. Coupled simulation of heat and moisture transport in air and porous materials for the assessment of moisture related damage. Building and Environment 2009, 44, 2176-2184.

48. Talukdar, P.; Osanyintola, O.F.; Olutimayin, S.O.; Simonson, C.J. An experimental data set for benchmarking 1-D, transient heat and moisture transfer models of hygroscopic building materials. Part II: experimental, numerical and analytical data. International Journal of Heat and Mass Transfer 2007, 50, 4915-4926.

49. Janssens, A.; Woloszyn, M.; Rode, C.; Sasic-Kalagasidis, A.; De Paepe, M. From EMPDto CFD: overview of different approaches for heat air and moisture modeling, in: C. Rode, H. Hens, H. Janssen (Eds.), Proceedings of the IEA ECBCS Annex 41Closing Seminar, Dept. of Civil Engineering, Technical University of Denmark, Copenhagen, Denmark, 2008, pp. 9-20

50. Menghao, Q.; Belarbi, R. Development of an analytical method for simultaneous heat and moisture transfer in building materials utilizing transfer function method. Journal of Materials in Civil Engineering 2005, 17 (5), $492-497$.

51. Xiaoshu, L. Modeling of heat and moisture transfer in buildings, I model program. Energy Build. 2002, 34, 1033-1043.

52. Kulasiri, D.; Woodhead, I. On modelling the drying of porous materials: analytical solutions to coupled partial differential equations governing heat and moisture transfer. Mathematical Problems in Engineering 2005, 3, $275-291$.

53. Chang, W.J.; Weng, C.I. An analysis solution to coupled heat and mass diffusion transfer in porous materials. Int. J. Heat Mass Transfer 2000, 43, 3621-3632.

54. Wijeysundera, N.E.; Hawlader, M.N.A. Effect of condensation and liquid transport on the thermal performance of fibrous insulation. Int. J. Heat Mass Transfer 1992, 35, 2605- 2616.

55. Wijeysundera, N.E.; Zheng, B.F. Numerical simulation of the transient moisture transfer through porous insulation. Int. J. Heat Mass Transfer 1995, 39, 995- 1003.

56. Hildebrandta, J.; Hagemann, N.; Thrän, D. The contribution of wood-based construction materials for leveraging a low carbon building sector in europe. Sustainable Cities and Society 2017, 34, 405-418.

57. Watchman, M.; Potvin, A.; Demers, C.M.H. Wood and comfort: a comparative case study of two multifunctional rooms. BioResources 2017, 12(1), 168-182.

58. Poirier, G.; Demers, C.M.H.; Potvin, A. Experiencing wooden ambiences with nordic light : scale model comparative studies under real skies. BioResources 2017, 12(1), 1924-1942.

59. Yuan, J.; Farnham, C.; Kazuo, E. Optimum insulation thickness for building exterior walls in 32 regions of China to save energy and reduce $\mathrm{CO}_{2}$ emissions. Sustainability 2017, 9(1711), 1-13; doi:10.3390/su9101711.

60. Ramage, M.H.; Burridge, H.; Busse-Wicher, M.; Fereday, G.; Reynolds, T.; Shah, D.U.; Wu, G.; Yu, L.; Fleming, P.; DensleyTingleye, D.; Allwood, J.; Dupree, P.; Linden, P.F.; Scherman, O.; The wood from the trees: the use of timber in construction. Renewable and Sustainable Energy Reviews 2017, 68, 333-359.

61. Pajchrowski, G.; Noskowiak, A.; Lewandowska, A.; Strykowski, W. Wood as a building material in the light of environmental assessment of full life cycle of four buildings. Construction and Building Materials 2014, 52, 428-436.

62. Rode, C.; Holm, A.; Padfield, T. A review of humidity buffering in the interior spaces. Journal of Thermal Envelope and Building Science 2004, 27 (3), 221-226. 
63. Younsi, R.; Kocaefe, D.; Kocaefe, Y. Three-dimensional simulation of heat and moisture transfer in wood. Applied Thermal Engineering 2006, 26, 1274-1285

64. Simonson, C. J.; Salonvaara, M.; Ojanen, T. The effect of structures on indoor humidity - possibility to improve comfort and perceived air quality. Indoor Air 2002, 12, 243-251.

65. Hens, H. Modelling, Final Report, IEA ECBCS Annex 24, KU Leuven, Belgium (1996).

66. Simonson, C.J.; Salonvaara, M.; Ojanen, T. ImprovingIndoor Climate and Comfort with Wooden Structures, Espoo,Finland, VTT Publications, (2001a) 431, 192 pages + App. 91 pages.

67. Simonson, C.J.; Salonvaara, M.; Ojanen, T. (2001b) Moisture content of indoor air and structures in buildings with vapour permeable envelopes. In: Proceedings (CD) of Performance of Exterior Envelopes of Whole Buildings VIII: Integration of BuildingEnvelopes, Clearwater Beach, Florida. ASHRAE.

68. Simonson, C.J.; Ojanen, T. (2000) Moisture performance of buildings with, no plastic vapour retarder in cold climates.In: Seppa“ nen, O. and Sa“ teri, J.(eds) Proceedings of Healthy Buildings 2000, Finnish Society of Indoor Air Quality and Climate, Vol. 3, 477-482.

69. Salonvaara, M.; Karagiozis, A. (1994)Moisture transport in building envelopes using an approximate factorization solution method. In: Gottlieb, J.and Ethier, C. (eds) Proceedings of the Second Annual Conference of the CFD Society of Canada, Toronto, Canada, June, 317-326.

70. Salonvaara, M.; Kokko, E. (1999) Heat and Mass Transfer in Cellulose Fibre Insulation Structures Sellukuiturakenteiden la“mmo“ nja aineensiirtotekninen toiminta), Espoo, Finland, VTT Research Notes, 1946, ISBN 951-38-5650-X, 951- 38-56518, http://www.inf.vtt.fi/pdf/tiedotteet/1999/T1946.pdf (in Finnish).

71. Salonvaara, M.H. (1998) Prediction of hygrothermal performance of building envelope parts coupled with indoor climate, ASHRAE Transactions, 104, 908-918.

72. Talukdar, P.; Osanyintola, O.F.; Olutimayin, S.O.; Simonson, C.J. An experimental data set for benchmarking 1-D, transient heat and moisture transfer models of hygroscopic building materials. Part II: experimental, numerical and analytical data. International Journal of Heat and Mass Transfer 2007, 50, 4915-4926

73. Watt, D.; Sjöberg, S.; Wahlgren, P. Hygrothermal performance of a light weight timber wall assembly with an exterior air barrier. Energy Procedia 2015, 78, 1419 - 1424.

74. Simo-Tagne, M.; Remond, R. ; Kharchi, R.; Bennamoun, L.; Ndukwu, M.C.; Rogaume, Y. Modeling, numerical simulation and validation of the hygrothermal transfer through a wooden building wall in Nancy, France. Thermal Science and Engineering Progress 2021, 22. 100808.

75. Berger, J.; Dutykh, D.; Mendes, N.; Rysbaiuly, B. A new model for simulating heat, air and moisture transport in porous building materials. International Journal of Heat and Mass Transfer 2019, 134, 1041-1060.

76. Simo-Tagne, M.; Remond, R.; Rogaume, Y.; Zoulalian, A.; Bonoma, B. Modeling of coupled heat and mass transfer during drying of tropical woods. International Journal of Thermal Sciences 2016, 109, 299-308.

77. Simo-Tagne, M.; Bennamoun, L.; Léonard, A.; Rogaume, Y. Modeling, numerical simulation and validation of a convective dryer in steady conditions: case study of tropical woods. International Journal of Modelling and Simulation 2020, 40:2, 143-161.

78. Simo-Tagne, M.; Rémond, R.; Rogaume, Y.; Zoulalian, A.; Perré, P. Characterization of sorption behaviour and mass transfer properties of four central Africa tropical woods: ayous, sapele, frake, lotofa. Maderas. Ciencia y tecnología 2016, 18(1): 207 -226 .

79. Simo-Tagne, M.; Ndukwu, M.C.; Azese, M.N. Experimental Modelling of a Solar Dryer for Wood Fuel in Epinal (France). Modelling 2020, 1, 39-52. doi: 10.3390/modelling1010003 